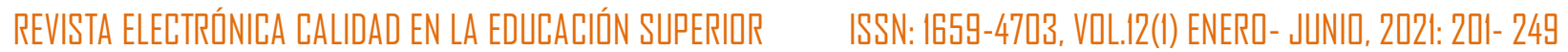

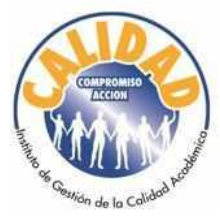

Vicerrectoría Académica

Instituto de Gestión de la Calidad Académica

Co-creando Excelencia

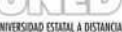

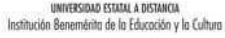

http://revistas.uned.ac.cr./index.php/revistacalidad

Coгreo electrónica: revistacalidad国uned.ac.сг

\title{
Reacreditación de carreras de la Universidad de Costa Rica: lo cumplido y lo pendiente.
}

Reaccreditation of university degrees at the University of Costa Rica: accomplishments and pending issues.

Reakkreditierung von Hochschulabschlüssen an der Universidad de Costa Rica: Was wurde erreicht und was ist noch offen.

Elsiana Guido-Guido1

elsiana.guido@ucr.ac.cr Universidad de Costa Rica, Costa Rica

(1) https://orcid.org/0000-0002-2838-6385

DOl: http://dx.doi.org/10.22458/caes.v12i1.3508

Volumen 12, Número 1

30 de mayo de 2021

pp. 201- 249

Recibido: 13 de noviembre del 2020

Aprobado: 23 de abril de 2021

1 Asesora académica e investigadora del Centro de Evaluación Académica, de la Universidad de Costa Rica.Costa Rica. Correo electrónico: elsiana.guido@ucr.ac.cr. (Dhttps://orcid.org/0000-0002-2838-6385

Reacreditación de carreras de la Universidad de Casta Rica: lo cumplida y lo pendiente.

Elsiana Guida-Guida

DII: http://dx.dai..rg//10.22458/caes.v12il.3508

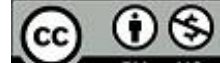

Artícula protegida par licencia Creative Commans 


\title{
Resumen
}

En este artículo se analiza el contenido de quince compromisos de mejoramiento (CM) presentados por carreras de la Universidad de Costa Rica (UCR) que se han reacreditado por primera vez, con la Agencia Sistema Nacional de Acreditación de la Educación Superior (SINAES) utilizando el Manual de acreditación oficial de carreras de grado vigente, que corresponde al año 2009. Estos CM corresponden a carreras reacreditadas entre los años 2011 y el primer semestre del 2020. Los hallazgos obtenidos en este estudio se presentan de acuerdo con las cuatro dimensiones y los veintiún componentes del modelo de acreditación, de manera que se detallan los criterios y componentes que, con mayor frecuencia, presentan debilidades en los CM analizados. Según esto, los CM presentan debilidades en todas las dimensiones del modelo; asimismo, contienen criterios con debilidades en todos los componentes. Los componentes con mayor cantidad de criterios asociados a una debilidad son correspondencia con el contexto, plan de estudios, personal académico, infraestructura, gestión de la carrera, investigación, vida estudiantil y graduados. Más de una cuarta parte de los criterios no están contemplados como debilidades. A partir de los hallazgos, se presentan características que comparten las carreras reacreditadas, considerando las dimensiones del modelo, así como los asuntos atendidos y pendientes a nivel institucional.

Palabras clave: acreditación, reacreditación, calidad de la educación superior, compromisos de mejoramiento, debilidades, Universidad de Costa Rica, agencia SINAES.

\begin{abstract}
This article analyzes the content of fifteen self-improvement commitment (SIC) plans presented by careers of the University of Costa Rica that have been reaccredited for the first time, by the National System of Higher Education Accreditation Agency (SINAES), based on the official accreditation manual for undergraduate programs (2009), during the period of 2011 and the first semester of 2020. The findings obtained in this study are presented according to the four dimensions and the twenty-one components which are included in the accreditation model. Criteria and components most frequently considered to need some degree of improvement in the SIC plans are closely examined. In all cases, the SIC plans presented improvement needs in each of the four dimensions of the model, as well as criteria with weaknesses in all components of each dimension. The components with the most improvement needs are related with the context, curriculum, academic staff, infrastructure, career management, research, student life and graduates. Over a quarter of the criteria did not show any need of improvement. Based on the findings, common aspects of the re-accredited careers are presented, considering the dimensions of the model as well as the issues addressed and pending at the institutional level.
\end{abstract}

Keywords: Accreditation, reaccreditation, quality of higher education, self-improvement commitment, weaknesses, University of Costa Rica, SINAES Agency.

Reacreditación de carreras de la Universidad de Costa Rica: lo cumplida y lo pendiente.

Elsiana Guida-Guida

DOI: http://dx.dai.arg/l0.22458/caes.v|2il.3508

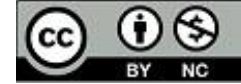

Artícula prategida par licencia Creative Cammans 


\section{Kurzfassung}

In diesem Artikel wird der Inhalt von 15 Verbesserungsmaßnahmen von Studiengängen der Universidad de Costa Rica analysiert, die erstmalig von der Agencia Sistema Nacional de la Educacion Superior (SINAES) reakkreditiert wurden. Benutzt wurde das Handbuch der offiziellen Akkreditierung von Studiengängen aus dem Jahr 2009, zwischen 2011 bis zum ersten Semester 2020. Die erlangten Erkenntnisse dieser Studie werden gemäß der vier Dimensionen und der 21 Komponenten des Akkreditierungsmodells vorgestellt, sodass die Kriterien und Inhalte einzeln aufgeführt werden, die am häufigsten Schwächen der analysierten Verbesserungsmaßnahmen zeigen. Die Verbesserungsmaßnahmen zeigen demnach Schwächen in allen Bereichen des Modells, ebenfalls beinhalten sie Kriterien mit Schwachstellen in allen Komponenten. Die Komponenten mit den meisten Kriterien, die mit Schwachstellen assoziiert werden können, sind Berufsfeldbezug des Studiengangs, Lehrplan, akademisches Personal, Infrastruktur, Karrieremanagement, Forschung, Leben der Studenten und Graduierten. Mehr als ein Viertel der Kriterien sind nicht als Schwachstellen zu sehen. Seit dem Erlangen der Erkenntnisse, bietet sich ein allgemeines Profil der reakkreditieren Studiengänge dar, berücksichtigt werden der Umfang des Modells, genauso wie die behandelten und offenen Themen auf institutioneller Ebene.

Schlüsselwörter: Akkreditierung, reakkreditierung , Qualität der Hochschulbildung, Verbesserungsmaßnahmen von Studiengängen, Schwächen, Universität von Costa Rica, SINAES Agentur.

\section{Introducción ${ }^{2}$}

El presente artículo tiene como fin analizar los Compromisos de Mejoramiento (CM) presentados por quince carreras de la Universidad de Costa Rica (UCR) que han recibido el certificado de reacreditación por parte de la Agencia Sistema Nacional de Acreditación de la Educación Superior (SINAES), para identificar los componentes y criterios que, con mayor frecuencia, no son cumplidos por las carreras y que por lo tanto presentan debilidades asociadas a ellos. Además, a partir de los hallazgos encontrados, se muestran características generales de las carreras reacreditadas, considerando las dimensiones del modelo de la agencia SINAES, así como del análisis de los objetivos contemplados en los CM. Finalmente

\footnotetext{
${ }^{2}$ Se agradece a Ana Lorena Marín Solano, por su importante labor asistencial en esta investigación.
}

Reacreditación de carreras de la Universidad de Costa Rica: lo cumplida y lo pendiente.

Elsiana Guida-Guida

DDI: http://dx.dai.org//1.22458/caes.v12ii.3500

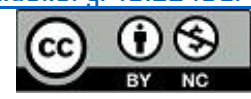


se mencionan algunos aportes importantes de la UCR, que contribuyen a la atención institucional de algunas de las debilidades identificadas.

\section{Primeras acreditaciones en la Universidad de Costa Rica}

La UCR fue la primera institución de educación superior pública del país, en acreditar carreras ante la agencia oficial SINAES. En el mes de julio del año 2001 se acreditaron las dos primeras carreras de la UCR; años después, al vencer el período de acreditación, estas carreras constituyeron, a su vez, las dos primeras reacreditaciones realizadas por la recién creada agencia.

La primera carrera acreditada de la UCR, del área de Ciencias Sociales, obtuvo un certificado que le otorgó tal condición por un período de cuatro años (SINAES, 2001a). Para su proceso de autoevaluación, esta carrera utilizó el Manual de Acreditación -Convocatoria año 2000, el cual fue aprobado en la sesión No. 43 del Consejo de SINAES, celebrada en el mes de mayo del año 2000. Esta primera carrera presentó un plan de mejoramiento, ya que así se denominaba al documento que recogía las debilidades que debían atenderse, organizado de acuerdo con los componentes del modelo vigente. De este modo, el documento estaba conformado por diez grandes objetivos desagregados de la manera siguiente: tres objetivos en el componente personal académico, dos objetivos en el componente currículum, dos objetivos en el componente administración de la carrera, dos objetivos en el componente infraestructura y equipamiento y un objetivo en el componente impacto y pertinencia.

La segunda carrera acreditada en la UCR, que inició su proceso de autoevaluación en el año 1998 con el documento titulado Guía para la autoevaluación de Carreras y Programas, Unidad Técnica de Apoyo 1998, obtuvo la acreditación en el mes de julio de 2001, por un período de cuatro años (SINAES, 2001b). Esta carrera, del área de la Salud, presentó un CM compuesto

\section{Reacreditación de carreras de la Universidad de Costa Rica: lo cumplida y lo pendiente. Elsiana Guida-Guida DOI: http://dx.dai.org//10.22458/caes.v|Zil.3508$$
\text { (c) (1) (8) }
$$ 
por cinco programas los cuales contenían a su vez uno o varios objetivos específicos, que se citan seguidamente: 1- Programa de mejoramiento de la calidad de la enseñanza de la carrera, que contenía 5 objetivos concretos relacionados. 2- Programa de desarrollo del personal académico, compuesto por tres objetivos. 3- Programa de apoyo académicodocente, integrado por dos objetivos. 4- Programa de gestión eficiente, integrado por dos objetivos y 5-Vinculación interinstitucional, compuesto por un objetivo.

Casi 20 años después de esas primeras dos acreditaciones, la UCR cuenta con un total de 37 carreras acreditadas o reacreditadas (SINAES, base datos agosto, 2020).

\section{Breve evolución de la agencia SINAES, desde la perspectiva de sus modelos de acreditación}

En sus casi dos décadas de funcionamiento, la agencia SINAES ha puesto a disposición de las carreras y de los programas universitarios, dos guías oficiales diferentes para realizar la autoevaluación. La primera de ellas, del año 2000, titulada Manual de Acreditación Convocatoria año 2000 constaba de seis componentes a saber: personal académico, currículum, estudiantes, administración, infraestructura y equipamiento e impacto y pertinencia. Este Manual estaba compuesto por 54 criterios y 8 estándares.

La segunda guía para la autoevaluación de carreras empezó a regir en el año 2009, con el título Manual de acreditación oficial de carreras de grado del Sistema Nacional de Acreditación de la Educación Superior. El documento, según se indica, fue elaborado por el SINAES “... en estrecha colaboración con diversos actores claves de la educación superior costarricense; entre éstos, las universidades que se han adherido al sistema". (SINAES, 2000, p.2) y fue aprobado en la sesión $n^{\circ} 509$ del Consejo de la Agencia en el mes de julio del año 2008.

Reacreditación de carreras de la Universidad de Costa Rica: lo cumplida y lo pendiente.

Elsiana Guido-Guido

DOI: http://dx.dai.arg//10.22458/caes.v|Zil.3508

(c)

Artícula prategida par licencia Creative Cammans 
El Manual de acreditación del año 2009, vigente hoy en día, consta de dimensiones, componentes, criterios y estándares. Las dimensiones son cuatro, y se refieren, como lo apunta la agencia a "... un entorno que contextualiza, unos recursos o insumos necesarios para realizar el proceso educativo, el proceso mismo y unos resultados "(SINAES, 2009, p. 37). Estas dimensiones contemplan un total de veintiún componentes, que son "... categorías de análisis que permiten desagregar las dimensiones del modelo..." (SINAES, 2009, p. 39), tal y como se explica seguidamente: 1- La dimensión relación con el contexto, contiene 3 componentes, 2-La dimensión recursos abarca 7 componentes, 3- La dimensión proceso educativo está conformada por 6 componentes y 4- La dimensión resultados implica 3 componentes. Vale señalar que la Guía contiene también, dos componentes que no están asociados a una dimensión, pero que sí se desagregan en criterios.

Cada componente tiene un número determinado de criterios asociados, que oscilan entre uno y veinte; de este modo, el componente con menor número de criterios es proyección de la carrera y el que más tiene es el componente gestión de la carrera, de la dimensión proceso educativo. En total, el Manual contiene 171 criterios. De acuerdo con el Modelo de la agencia SINAES, el criterio es "... un principio definido a priori, relacionado con el deber ser, sirve para construir los juicios de evaluación y analizar niveles de calidad. El criterio delimita un campo o aspecto de análisis de la carrera" (SINAES, 2009, p. 40). Si se analiza el énfasis del modelo propuesto, se tiene que poco más de un $70 \%$ de los criterios se asocian a dos dimensiones, a saber: proceso educativo y recursos.

Finalmente, los 34 estándares que contiene el Manual están vinculados a los componentes; sin embargo, no todos los componentes tienen estándares asociados. El estándar es, de acuerdo con la agencia, “... una norma que se convierte en un requisito o condición. El

Reacreditación de carreras de la Universidad de Costa Rica: lo cumplida y lo pendiente.

Elsiana Guido-Guido

DQI: http://dx.dai.org/10.22458/caes.v12il.3508

(c)

Artícula prategida par licencia Creative Cammans 
estándar define el rango en que resulta aceptable el nivel de calidad que se alcanza en un determinado campo o aspecto de la carrera". (SINAES, 2009, p. 40). Si se analiza dónde se ubica el énfasis de los estándares del modelo, se tiene que los componentes personal académico y graduados son los que mayor cantidad de estándares contienen, ya que les corresponden siete y cinco estándares, respectivamente. Además, es importante resaltar que seis, de los veintiún componentes, no cuentan con estándares relacionados, estos son: admisibilidad, proceso de admisión e ingreso, personal administrativo, finanzas y presupuesto, desempeño estudiantil sostenibilidad.

Además de los cambios mencionados en los manuales de acreditación, el SINAES ha tenido dos cambios significativos, en dos esferas diferentes, a lo largo de estas casi dos décadas de vida: una referida a su ámbito de acción y otra relacionada con su constitución. Dentro del primer cambio se menciona que, en la actualidad, el SINAES puede acreditar no solo carreras de grado y programas de postgrado pertenecientes a las universidades estatales y privadas del país (como quedó consignado en la Ley No. 8256), sino que también está facultado, a partir del año 2010, para acreditar instituciones y carreras pertenecientes a la educación superior no universitaria (CINDA, 2016, p.33-34). Dentro del segundo cambio significativo, se tiene por un lado la adherencia al sistema de instituciones parauniversitarias y, por otra parte, la variación en lo que respecta a su financiamiento, ya para el año 2010 la ley N8798 le asigna presupuesto propio a la agencia.

A pesar de lo anterior, los datos del total de instituciones adheridas al sistema resultan poco significativos, dada la cantidad y pluralidad de Instituciones de Educación Superior que existen en el país. Esta situación puede deberse a varios motivos; sin embargo, al respecto se coincide con CINDA (2016) en los dos aspectos principales que señala en su informe, que se refieren a la voluntariedad de la acreditación y a los incentivos para adherirse, cuando

\section{Reacreditación de carreras de la Universidad de Costa Rica: lo cumplida y la pendiente.}

Elsiana Guida-Guida

DDI: http://dx.dai.org//0.22458/caes.v12il.3508

(c) $($ i) (8) 
mencionan que “... por el carácter voluntario de la acreditación y la insuficiencia de incentivos efectivos para la incorporación al SINAES solo un $28,6 \%$ de las IES universitarias del país y un $12 \%$ de las IES no universitarias forman parte de SINAES" (p. 34).

Actualmente, el SINAES está conformado por miembros plenos, asociados y por instituciones parauniversitarias. Son diecinueve IES (de carácter público y privado) las que conforman el sistema como instituciones miembros plenos, porque "... han cumplido los requisitos de afiliación y mantienen vigente la acreditación oficial mínima de carreras o programas de posgrado". Destaca que, en el listado de miembros asociados, se encuentran ocho IES (todas de naturaleza privada) que "... han sido admitidas temporalmente por el SINAES, bajo la condición de cumplir los compromisos contemplados en el Reglamento de Membresía", y también figuran seis instituciones parauniversitarias, cuyo ingreso quedó estipulado en la Ley 8798. (SINAES, 2020a).

La UCR es, en la actualidad, la Universidad pública costarricense con más carreras acreditadas y reacreditadas por el SINAES ya que, según datos de mitad del año 2020, a esta Universidad le corresponde un poco más del 18\% del total de carreras acreditadas y reacreditadas, vigentes, por esa agencia. (SINAES, 2020b).

Se tiene de este modo, en este análisis de la evolución de la agencia, que no todas las IES adheridas al sistema han acreditado carreras y que sigue aún pendiente la definición del papel que podría tener la acreditación institucional en el incremento de las acreditaciones de carreras o en la disminución de aspectos, de carácter institucional, que aparecen como debilidades en los CM. Se considera que la no puesta en práctica de la acreditación de instituciones, por parte de la agencia, repercute negativamente en el incremento cuantitativo de los procesos de acreditación en el país.

Reacreditación de carreras de la Universidad de Costa Rica: lo cumplida y lo pendiente.

Elsiana Guida-Suida

DQI: http://dx.dai.org/10.22458/caes.v12il.3508

(c) $\underset{\mathrm{BY}}{(1)}(\mathrm{NC}$

Artícula prategida par licencia Creative Cammans 


\section{La reacreditación de carreras en la Universidad de Costa Rica}

Las reacreditaciones de carreras con la agencia SINAES iniciaron en la UCR en el año 2006, cuando se le venció el período de acreditación a las dos primeras carreras que fueron acreditadas en el año 2001; como se indicó antes, las dos primeras carreras que se reacreditaron pertenecen a las áreas de Ciencias Sociales y de Salud.

En la Tabla 1 se muestra la distribución de las veintiún carreras reacreditadas por primera vez en la UCR (Sede Rodrigo Facio y Sede de Occidente) desde el año 2006 hasta inicios del año 2020. Solo se incluyen las carreras que obtuvieron su primera reacreditación con la agencia, es decir, no se incluyen las carreras que han obtenido la segunda o tercera reacreditación con la agencia SINAES.

Es importante mencionar que en el año 2010 se reacreditaron las dos primeras carreras de la UCR, de la Sede Rodrigo Facio, para cuyo proceso de autoevaluación se utilizó el Manual de acreditación oficial de carreras de grado del Sistema Nacional de Acreditación de la Educación Superior, es decir la segunda guía publicada por la agencia en el año 2009.

Reacreditación de carreras de la Universidad de Costa Rica: lo cumplida y lo pendiente.

Elsiana Guida-Guida

DII: http://dx.dai.org//1.22458/caes.v12ii.3500

(c) (1) \& 
Tabla 1. Universidad de Costa Rica. Cantidad de carreras reacreditadas por primera vez ante la agencia SINAES, según año y área a la que pertenecen. 2006- 2020

\begin{tabular}{|c|c|c|c|c|c|}
\hline Año & Área & $\begin{array}{l}\text { Cantidad } \\
\text { de carreras } \\
\text { reacreditad } \\
\text { as por } \\
\text { primera vez }\end{array}$ & Año & Área & $\begin{array}{l}\text { Cantidad de } \\
\text { carreras } \\
\text { reacreditada } \\
\text { s por } \\
\text { primera vez }\end{array}$ \\
\hline \multirow[t]{2}{*}{2006} & Salud & 1 & 2014 & Salud & 1 \\
\hline & $\begin{array}{l}\text { Ciencias } \\
\text { Sociales }\end{array}$ & 1 & 2015 & $\ldots$ & 0 \\
\hline 2007 & $\ldots$ & 0 & \multirow[t]{5}{*}{2016} & $\begin{array}{l}\text { Ciencias } \\
\text { Agroalimentarias }\end{array}$ & 2 \\
\hline 2008 & Salud & 1 & & Salud & 1 \\
\hline 2009 & 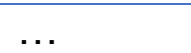 & 0 & & Artes y Letras & 1 \\
\hline \multirow[t]{2}{*}{2010} & $\begin{array}{l}\text { Ciencias } \\
\text { Básicas }\end{array}$ & 1 & & Ciencias Sociales & 1 \\
\hline & $\begin{array}{l}\text { Ciencias } \\
\text { Sociales }\end{array}$ & 1 & & Ciencias Básicas & 1 \\
\hline 2011 & $\begin{array}{l}\text { Ciencias } \\
\text { Sociales }\end{array}$ & 2 & 2017 & $\ldots$ & 0 \\
\hline 2012 & $\begin{array}{l}\text { Ciencias } \\
\text { Sociales }\end{array}$ & 2 & 2018 & Ciencias Sociales & 2 \\
\hline \multirow[t]{2}{*}{2013} & Salud & 1 & 2019 & Ciencias Sociales & 1 \\
\hline & & & 2020* & Ciencias Sociales & 1 \\
\hline
\end{tabular}

Nota: No se incluye a las carreras del área de las Ingenierías.

*Incluye reacreditaciones otorgadas al primer semestre de 2020.

Fuente: elaboración propia con base en datos del Centro de Evaluación Académica.

En el Manual de acreditación oficial de carreras de grado del Sistema Nacional de Acreditación de la Educación Superior, se establece la reacreditación de carreras como un proceso. En este proceso, el Consejo Nacional de Acreditación, órgano de máxima decisión de la agencia, tiene la responsabilidad de verificar el cumplimiento y mejoramiento de todas las etapas que conlleva la reacreditación (SINAES, 2009, p. 14).

Reacreditación de carreras de la Universidad de Costa Rica: lo cumplida y la pendiente.

Elsiana Guida-Guida

DQI: http://dx.dai.org/10.22458/caes.v12il.3508

(c) $\underset{\mathrm{BY}}{(\mathrm{i}) \mathrm{SC}}$ 
Dentro del modelo evaluativo de esta agencia, se presentan orientaciones para que las carreras o programas realicen la reacreditación. En este sentido, en el documento referido, se menciona que en la fase de reacreditación" las carreras universitarias presentarán un informe que dé cuenta de los cambios ocurridos desde la acreditación oficial, de manera que se pueda valorar la evolución de tales carreras. "(SINAES, 2009, p. 39)

SINAES explica el significado de la reacreditación para una carrera como una "revalidación" de la condición de acreditada, como se indica seguidamente:

La acreditación se otorga por un periodo determinado, lo usual es que la primera vez sea por cuatro años. Una vez finalizado ese período, la carrera debe realizar nuevamente la Autoevaluación, así como recibir nuevamente la visita de los dos expertos internacionales y uno nacional (Evaluación externa). Para revalidar su acreditación (reacreditación) la carrera debe demostrar el mejoramiento de su calidad, que se otorga por un plazo de entre dos y ocho años. Así las cosas, la acreditación es un proceso cíclico, la carrera estará en un estado permanente de mejora. (SINAES, 2019)

Para la Red Iberoamericana para el Aseguramiento de la Calidad de la Educación Superior (RIACES), la reacreditación consiste en la renovación de la acreditación la cual se da en dos circunstancias: una vez que se termine la vigencia de la acreditación de la carrera o bien, cuando la carrera vuelve a cumplir los requisitos establecidos porque se han dado cambios sustantivos en la organización o en su estatus. (RIACES, s.f., p.29)

En la UCR una carrera obtiene la condición de reacreditada cuando la agencia vuelve a otorgarle la acreditación una vez que se le vence el período de la acreditación y opta por una

\section{Reacreditación de carreras de la Universidad de Costa Rica: lo cumplida y lo pendiente. Elsiana Guida-Guida DDI: http://dx.dai..rg//10.22458/caes.v12il.3508$$
\text { (c) }(\text { i) (8) }
$$ 
nueva; para esto, la carrera debe realizar un nuevo proceso de autoevaluación siguiendo el modelo vigente de la agencia, y seguir todo el proceso establecido que incluye la evaluación externa y la presentación de un nuevo CM con las debilidades encontradas en este proceso auto reflexivo. Resulta notorio que, dentro de su instrumental técnico, la agencia no cuenta, aún, con un manual específico para la reacreditación de las carreras por lo que, las carreras universitarias que han optado por este reconocimiento, han realizado el proceso de autoevaluación con la misma guía utilizada para su acreditación.

En resumen, la reacreditación puede entenderse como una renovación de la acreditación por parte de la agencia, una vez que se venza el período, tal y como quedó estipulado en el Artículo 17 de la Ley No. 8256 del SINAES, publicada en el año 2002. Actúa, de esta manera, como una continuación o reafirmación del compromiso que la carrera ha adquirido con la calidad, la evaluación constante y la mejora continua. Se obtiene, como se explicó, por un tiempo definido luego de un nuevo proceso de autoevaluación, de una evaluación externa y de la elaboración de un CM.

En su gestión de la calidad y de la mejora continua, una carrera puede obtener varias acreditaciones por parte de una agencia. La primera vez que se obtiene tal condición se denomina acreditación, pero una vez que la carrera decide continuar con los procesos ante la agencia, obtiene la denominada reacreditación; posteriormente, la carrera puede volverse a reacreditar y así sucesivamente. Para efectos de este estudio, se denominará acreditación a la primera vez que una carrera obtenga tal reconocimiento y a las sucesivas se les denominará primera reacreditación o segunda reacreditación, para diferenciarlas en cuanto a su secuencia en el tiempo.

\section{Metodología}

Reacreditación de carreras de la Universidad de Costa Rica: lo cumplida y la pendiente.

Elsiana Guida-Suida

DQI: http://dx.dai.org/10.22458/caes.v12ii.3508

(c) $\underset{\mathrm{BY}}{(1)}(\mathrm{NC}$

Artícula prategida par licencia Creative Cammans 
La investigación realizada analizó quince CM de carreras de la UCR que obtuvieron su primera reacreditación con la agencia SINAES entre los años 2011 y 2020. Se incluyeron los CM de carreras reacreditadas por primera vez, pertenecientes a la Sede Rodrigo Facio. Para efectos comparativos y analíticos del estudio, se tomaron los CM que fueron elaborados siguiendo lo contemplado en la segunda guía publicada por la agencia SINAES en el año 2009, titulada Manual de acreditación oficial de carreras de grado del Sistema Nacional de Acreditación de la Educación Superior. Es decir, no se tomaron en cuenta carreras que se reacreditaron por primera vez utilizando la primera guía de la agencia SINAES (del año 2000), ni se tomaron en consideración los CM de las segundas reacreditaciones, así como tampoco reacreditaciones de otras sedes universitarias, distintas a la Rodrigo Facio; tampoco fueron consideradas, para este estudio, carreras del área de las Ingenierías por haberse acreditado originalmente, la mayoría de ellas, con agencias extranjeras y un modelo diferente.

El objetivo del análisis fue identificar, en los $\mathrm{CM}$, los componentes y criterios del modelo que, con mayor frecuencia, son cumplidos, o no, por las carreras y que por lo tanto presentan debilidades asociadas a ellos. Además, a partir de los hallazgos encontrados, se realizó un análisis que permite evidenciar características generales de las carreras reacreditadas, considerando las dimensiones del modelo de la agencia SINAES y los objetivos contemplados en los CM.

El análisis descriptivo - analítico de los CM de carreras reacreditadas por primera vez con el modelo de autoevaluación la agencia SINAES del año 2009, se realizó de la manera siguiente: primero se contabilizaron los criterios contenidos en cada uno de los quince $\mathrm{CM}$, que se asocian a un objetivo; de este modo, se pudo obtener un listado de los criterios que presentan debilidades en por lo menos una de las carreras elegidas. Segundo, se agruparon los criterios asociados a algún objetivo, por componente y por dimensiones del modelo.

Reacreditación de carreras de la Universidad de Costa Rica: lo cumplida y lo pendiente.

Elsiana Guido-Guido

DQI: http://dx.dai.org/10.22458/caes.v12il.3508

(c) $($ ) () ()

Artícula prategida par licencia Creative Cammans 
Es importante mencionar que, para mantener el anonimato de las carreras y analizar los datos, las carreras se agruparon de acuerdo con las seis áreas en que se clasifican los conocimientos y saberes en la UCR; esto permitió determinar la existencia de alguna tendencia en cuanto a la prevalencia de los criterios con debilidades de acuerdo con las áreas y según los componentes y dimensiones del modelo de la agencia.

Vale anotar que, en la UCR, cada área de conocimiento incluye a varias carreras, tal y como se explica seguidamente: el área de Artes y Letras incluye carreras pertenecientes a las Facultades de Artes y de Letras. El área de Ciencias Sociales incluye a carreras de las Facultades de Derecho, Educación, Ciencias Económicas y Ciencias Sociales. Por otro lado, el área de Salud incluye a las Facultades de Medicina, Odontología, Microbiología y Farmacia. El área de Ciencias Agroalimentarias incluye carreras de la Facultad de Ciencias Agroalimentarias. El área de Ciencias incluye las carreras de la Facultad de Ciencias y finalmente el área de las Ingenierías está conformada por carreras de la Facultad de Ingeniería.

La agrupación de los criterios contenidos en los CM analizados se hizo de acuerdo con la clasificación del Manual de acreditación vigente, que contiene un total de 171 criterios que responden a veintiún componentes y cuatro dimensiones. Estos resultados presentan los criterios más frecuentes de acuerdo con el componente al que pertenecen y a la dimensión respectiva.

Posteriormente se realizó un análisis de los resultados obtenidos y de los objetivos propuestos por las carreras en sus $\mathrm{CM}$, que agrupa en grandes categorías los hallazgos obtenidos y permiten establecer las características generales de las carreras reacreditadas.

Reacreditación de carreras de la Universidad de Costa Rica: lo cumplida y lo pendiente.

Elsiana Guida-Suida

DIII: http://dx.dai.org//1.22458/caes.v12il.3508

(c) $\underset{\mathrm{BY}}{(1)}(\mathrm{NC}$ 


\section{Resultados y su análisis}

Descripción general de las carreras reacreditadas

De las veintiún carreras que se han reacreditado por primera vez en la UCR, tanto en la Sede Rodrigo Facio como en la Sede de Occidente, durante el período comprendido entre los años 2011 y primer semestre del año 2020, para este estudio se analizaron quince CM que corresponden a carreras reacreditadas por primera vez con la agencia SINAES, pertenecientes únicamente a la Sede Rodrigo Facio, que utilizaron la Guía del año 2009 para su proceso de autoevaluación.

Según la delimitación anterior, fue en el año 2011 que se reacreditó la primera carrera en la UCR con estas condiciones, perteneciente al área de Ciencias Sociales. De este modo, si se clasifican estas carreras reacreditadas de acuerdo con las áreas de conocimiento de la UCR, se tiene que ocho de estas carreras pertenecen al área de Ciencias Sociales, una carrera es del área Ciencias Básicas, tres carreras son del área de Salud, dos carreras pertenecen al área de Agroalimentarias y una carrera es del área de Letras, tal y como se muestra en la Tabla 2.

Reacreditación de carreras de la Universidad de Costa Rica: lo cumplida y lo pendiente.

Elsiana Guido-Guido

DII: http://dx.dai.org/l0.22458/caes.v12il.3508

(c) (i) (5) 
Tabla 2. Universidad de Costa Rica. Sede Rodrigo Facio. Distribución del número de carreras reacreditadas por primera vez, utilizando la Guía del año 2009, por año y área de conocimiento. 2011-2020*

\begin{tabular}{|c|c|c|c|c|c|c|c|c|c|c|c|}
\hline Área & $\begin{array}{l}201 \\
1\end{array}$ & $\begin{array}{l}201 \\
2\end{array}$ & $\begin{array}{l}201 \\
3\end{array}$ & $\begin{array}{l}201 \\
4\end{array}$ & $\begin{array}{l}201 \\
5\end{array}$ & $\begin{array}{l}201 \\
6\end{array}$ & $\begin{array}{l}201 \\
7\end{array}$ & $\begin{array}{l}201 \\
8\end{array}$ & $\begin{array}{l}201 \\
9\end{array}$ & $\begin{array}{l}202 \\
0\end{array}$ & $\begin{array}{l}\text { TOTA } \\
\text { L }\end{array}$ \\
\hline $\begin{array}{l}\text { Ciencias } \\
\text { Sociales }\end{array}$ & 1 & 2 & 0 & & 0 & & 1 & 2 & 1 & 1 & 8 \\
\hline Salud & & & & 2 & & 1 & & & & & 3 \\
\hline $\begin{array}{l}\text { Ciencias } \\
\text { Agroalimentari } \\
\text { as }\end{array}$ & & & & & & 2 & & & & & 2 \\
\hline $\begin{array}{l}\text { Ciencias } \\
\text { Básicas }\end{array}$ & & & & & & & 1 & & & & 1 \\
\hline Letras & & & & & & 1 & & & & & 1 \\
\hline TOTAL & 1 & 2 & 0 & 2 & 0 & 4 & 2 & 2 & 1 & 1 & 15 \\
\hline
\end{tabular}

Nota: *Incluye reacreditaciones hasta el primer semestre del año 2020.

No incluye el área de las Ingenierías.

Fuente: elaboración propia con base en datos del Centro de Evaluación Académica.

De acuerdo con los datos de la Tabla 2, en la Sede Rodrigo Facio de la UCR se han reacreditado por primera vez, en promedio, 1.5 carreras por año, durante el período comprendido entre los años 2011-2020, utilizando la Guía del SINAES del año 2009. En el año 2016 se otorgaron 4 reacreditaciones y esto lo constituye en el año en que más reacreditaciones se han obtenido en la historia de la UCR. En los años 2013 y 2015 no hubo reacreditaciones con estas características.

Criterios contenidos en los CM que presentan debilidades y criterios no asociados a debilidades.

Reacreditación de carreras de la Universidad de Costa Rica: lo cumplida y lo pendiente.

Elsiana Guido-Guido

DQI: http://dx.dai.org/10.22458/caes.v12il.3508

(c) $(1)$ ()

Artícula prategida par licencia Creative Cammans 
De los 171 criterios que contiene el Manual, 27 es el promedio de criterios que presentan debilidades en los CM de las carreras reacreditadas estudiadas. El rango numérico de criterios asociados a debilidades se ubica entre 13, que corresponde a una carrera del Área de Ciencias Agroalimentarias, y 51 criterios de una carrera del Área de Letras. En la Tabla 3 se desglosa el promedio de criterios con debilidades contenidos en los $\mathrm{CM}$, según el área de conocimiento

Tabla 3. Universidad de Costa Rica. Cantidad de carreras reacreditadas por primera vez con el Manual del año 2009 y promedio de criterios con debilidades en los CM, por área de conocimiento, 2011 - 2020

\begin{tabular}{|l|l|l|}
\hline Área de conocimiento & $\begin{array}{l}\text { Número de } \\
\text { carreras } \\
\text { reacreditadas }\end{array}$ & $\begin{array}{l}\text { Promedio } \\
\text { criterios de } \\
\text { debilidad en CM }\end{array}$ \\
\hline Ciencias Sociales & 8 & 26.75 \\
\hline Salud & 3 & 26.33 \\
\hline $\begin{array}{l}\text { Ciencias } \\
\text { Agroalimentarias }\end{array}$ & 2 & 16 \\
\hline Ciencias Básicas & 1 & 25 \\
\hline Letras & 1 & 51 \\
\hline
\end{tabular}

Fuente: elaboración propia con base en datos del Centro de Evaluación Académica.

De acuerdo con los datos de la Tabla 3 y, tomando en consideración que la distribución de las carreras por área de conocimiento es desigual, las áreas de Ciencias Sociales y de la Salud son las que, en promedio, presentan un mayor número de criterios con debilidades, en sus CM (26.75 y 26.33 respectivamente).

Otro hallazgo derivado del análisis realizado es que de los 171 criterios que contiene el Manual del año 2009, los CM analizados contienen debilidades en poco más de un $73 \%$ de

Reacreditación de carreras de la Universidad de Costa Rica: lo cumplida y la pendiente.

Elsiana Guida-Guida

DQI: http://dx.dai.org/10.22458/caes.v12il.3508

(c) $\underset{\mathrm{Br}}{(\mathrm{ir})}$ 
ellos, es decir, se contabilizaron 126 criterios con debilidades, por lo que 45 criterios no se encuentran contenidos como debilidades en los CM estudiados de las carreras reacreditadas en la UCR. Es decir, más de una cuarta parte de los criterios no están contemplados como debilidades en alguno de los CM de las carreras analizadas de esta Universidad, como se detalla en la Tabla 4.

Tabla 4. Universidad de Costa Rica. Total de criterios sin y con debilidades en los CM de carreras reacreditadas por primera vez con el Manual del año 2009, en el periodo 2011 - 2020, información según dimensión y componente.

\begin{tabular}{|l|l|l|l|}
\hline $\begin{array}{l}\text { Dimensión/ } \\
\text { Componente }\end{array}$ & $\begin{array}{l}\text { Total de } \\
\text { criterios } \\
\text { según Manual }\end{array}$ & $\begin{array}{l}\text { Total de criterios } \\
\text { sin debilidades en } \\
\text { los CM }\end{array}$ & $\begin{array}{l}\text { Total de criterios } \\
\text { con debilidades } \\
\text { en los CM }\end{array}$ \\
\hline Admisibilidad* & 12 & 10 & 2 \\
\hline Relación con el Contexto & 10 & 1 & 9 \\
\hline Recursos & 55 & 8 & 47 \\
\hline Proceso Educativo & 67 & 17 & 50 \\
\hline Resultados & 17 & 4 & 13 \\
\hline Sostenibilidad* & 10 & 5 & 5 \\
\hline Total & 171 & $\mathbf{4 5}$ & $\mathbf{1 2 6}$ \\
\hline
\end{tabular}

Nota:* Es un componente, los demás son dimensiones.

Fuente: elaboración propia con base en datos de los Compromisos de Mejoramiento.

De los datos anteriores se deriva que los componentes Admisibilidad y Sostenibilidad presentan el mayor porcentaje de cumplimiento en las reacreditaciones de carreras de una universidad con las características y la trayectoria en el país como lo es la UCR, puesto que

Reacreditación de carreras de la Universidad de Casta Rica: la cumplida y lo pendiente.

Elsiana Guida-Guida

DQI: http://dx.dai.org/10.22458/caes.v12il.3508

(c) ${ }_{\mathrm{BY}}(\mathrm{F})$

Artícula protegida por licencia Creative Commans 
pocos de los criterios aparecen como debilidades en los CM estudiados. Por otro lado, se presentan debilidades asociadas al $90 \%$ de los criterios de la dimensión Relación con el contexto; en el $85 \%$ de la dimensión Recursos, en el $76 \%$ de la dimensión Resultados y en el $74 \%$ de los criterios de la dimensión Proceso Educativo.

\section{Dimensiones, componentes y criterios que concentran la mayoría de los criterios con debilidades}

Los criterios asociados con debilidades presentes en los CM, pertenecen a todas las cuatro dimensiones del modelo, es decir, se presentan debilidades en las dimensiones relación con el contexto, recursos, proceso educativo y resultados. Si se analizan los datos a partir de su agrupación por dimensiones, componentes y criterios se tiene lo que se desagrega seguidamente.

\subsubsection{Dimensión: Relación con el contexto}

Esta dimensión está compuesta por los siguientes tres componentes y número de criterios:

1.Componente información y promoción: contiene dos criterios.

2.Componente proceso de admisión e ingreso: contiene dos criterios.

3. Componente correspondencia con el contexto: contiene seis criterios.

Reacreditación de carreras de la Universidad de Costa Rica: lo cumplido y lo pendiente.

Elsiana Guida-Suida

DII: http://dx.dai.org//1.22458/caes.v12ii.3508

(c) (1) (8)

Artícula prategida par licencia Creative Cammans 
Tabla 5. Universidad de Costa Rica. Total de carreras reacreditadas con debilidades encontradas en la dimensión Relación con el contexto, según componentes del Manual del año 2009, por áreas de conocimiento de la Universidad.

\begin{tabular}{|c|c|c|c|c|c|c|}
\hline \multirow[b]{2}{*}{$\begin{array}{l}\text { Component } \\
\text { es } \\
\text { del Manual } \\
\text { de } \\
\text { acreditació } \\
\text { n SINAES }\end{array}$} & \multicolumn{6}{|c|}{$\begin{array}{l}\text { Número de carreras que presentan criterios con debilidades en sus } \\
\text { CM según área de conocimiento de la UCR }\end{array}$} \\
\hline & $\begin{array}{l}\text { Ciencias } \\
\text { Sociales } \\
(8 \\
\text { carreras } \\
\text { reacredita } \\
\text { das) }\end{array}$ & $\begin{array}{l}\text { Salud } \\
(3 \\
\text { carreras } \\
\text { reacredita } \\
\text { das) }\end{array}$ & $\begin{array}{l}\text { Ciencias } \\
\text { Agroalimen } \\
\text { tarias } \\
(2 \text { carreras } \\
\text { reacreditad } \\
\text { as) }\end{array}$ & $\begin{array}{l}\text { Ciencias } \\
\text { Básicas } \\
\text { (1 carrera } \\
\text { reacredita } \\
\text { da) }\end{array}$ & $\begin{array}{l}\text { Letras } \\
(1 \\
\text { carrera } \\
\text { reacredit } \\
\text { ada) }\end{array}$ & $\begin{array}{l}\text { Tota } \\
\text { I }\end{array}$ \\
\hline $\begin{array}{l}\text { Informació } \\
\text { n y y } \\
\text { promoción }\end{array}$ & 6 & 0 & 1 & 1 & 1 & 9 \\
\hline $\begin{array}{l}\text { Proceso de } \\
\text { admisión e } \\
\text { ingreso }\end{array}$ & 0 & 0 & 0 & 1 & 0 & 1 \\
\hline $\begin{array}{l}\text { Correspon } \\
\text { dencia con } \\
\text { el contexto }\end{array}$ & 6 & 0 & 1 & 1 & 1 & 9 \\
\hline
\end{tabular}

Fuente: elaboración propia con base en datos de los Compromisos de Mejoramiento.

De los datos de la Tabla 5, se tiene que más de la mitad de las carreras analizadas presentan debilidades en dos de los componentes de esta dimensión: información y promoción y correspondencia con el contexto, que están contenidos en los CM de nueve carreras.

En el componente información y promoción las debilidades se relacionan con dos criterios (1.1.1 y 1.1.2), que hacen referencia a la importancia de contar con medios que permitan el acceso público a información sobre diversos aspectos de la carrera (1.1.1), que está presente en seis CM; y el 1.1.2 que se refiere a que el estudiantado debe ser informado

Reacreditación de carreras de la Universidad de Costa Rica: lo cumplida y la pendiente.

Elsiana Guida-Guida

DQI: http://dx.dai.org/10.22458/caes.v12il.3508

(c) $($ i) (8)

Artícula prategida par licencia Creative Cammans 
sobre temas del plan de estudios, tiempo promedio de graduación, costos, normativa, fechas, trámites y servicios, que está presente en seis CM.

Por otro lado, los criterios que presentan debilidades de forma más frecuente, en el componente correspondencia con el contexto, son los siguientes:

- 1.3.4 Vinculación de la carrera con la correspondiente comunidad académica, para su retroalimentación y mejora: contenido en cinco $\mathrm{CM}$.

- 1.3.5 Aprovechamiento del entorno para experiencias prácticas del estudiantado, según los requerimientos de la carrera: presente en cinco $\mathrm{CM}$.

- 1.3.1 El plan de estudios debe responder al estado actual de avance o desarrollo de la disciplina -estado del arte- y a la realidad del contexto nacional e internacional, así como al mercado laboral: presente en cuatro $\mathrm{CM}$.

Finalmente, en esta dimensión destaca que solo una carrera presenta debilidades en el componente proceso de admisión e ingreso, pero se trataba de una prueba específica a la que debía de dársele seguimiento, adicional al examen de ingreso a la universidad; por lo tanto, puede decirse que este aspecto, de carácter más institucional, es cumplido por casi la totalidad de carreras analizadas.

\title{
6.2.2 Dimensión: Recursos
}

La dimensión recursos está compuesta por los siguientes componentes y número de criterios.

1. Componente Plan de estudios, contiene diecinueve criterios.

2. Componente Personal académico, contiene doce criterios.

3. Componente Personal administrativo, contiene cuatro criterios.

4.Componente Infraestructura, contiene ocho criterios.

\author{
Reacreditación de carreras de la Universidad de Costa Rica: la cumplida y lo pendiente. \\ Elsiana Guida-Guida \\ DII: http://dx.dai.org//10.22458/caes.v12il.3508 \\ (c) (i) (5) \\ Artícula protegida par licencia Creative Commans
}


5.Componente Centro de información y recursos, contiene cinco criterios.

6. Componente Equipo y materiales, contiene cinco criterios.

7. Componente Finanzas y presupuestos, contiene dos criterios.

Los datos de la Tabla 6 evidencian cómo esta dimensión concentra algunos componentes medulares en donde la totalidad de las carreras reacreditadas estudiadas, (quince), presentan criterios con debilidades, tal es el caso de los componentes plan de estudios e infraestructura. Además, destaca que carreras de todas las áreas de conocimiento presentan criterios con debilidades en los componentes plan de estudios, personal académico e infraestructura.

Tabla 6. Universidad de Costa Rica. Total de carreras reacreditadas con debilidades encontradas en la dimensión Recursos, según componentes del Manual del año 2009, por áreas de conocimiento de la Universidad.

\begin{tabular}{|c|c|c|c|c|c|c|}
\hline \multirow{2}{*}{$\begin{array}{l}\text { Componentes } \\
\text { del Manual de } \\
\text { acreditación } \\
\text { SINAES }\end{array}$} & \multicolumn{6}{|c|}{$\begin{array}{l}\text { Número de carreras que presentan criterios con debilidades en sus } \\
\text { CM según área de conocimiento de la UCR }\end{array}$} \\
\hline & $\begin{array}{l}\text { Ciencias } \\
\text { Sociales } \\
(8 \text { carreras } \\
\text { reacreditad } \\
\text { as) }\end{array}$ & $\begin{array}{l}\text { Salud } \\
\text { ( } 3 \text { carreras } \\
\text { reacreditad } \\
\text { as) }\end{array}$ & $\begin{array}{l}\text { Ciencias } \\
\text { Agroalimen } \\
\text { tarias } \\
\text { ( } 2 \text { carreras } \\
\text { reacreditada } \\
\text { s) }\end{array}$ & $\begin{array}{l}\text { Ciencias } \\
\text { Básicas } \\
(1 \text { carrera } \\
\text { reacreditad } \\
\text { a) }\end{array}$ & $\begin{array}{l}\text { Letras } \\
\text { (1 carrera } \\
\text { reacredit } \\
\text { ada) }\end{array}$ & $\begin{array}{l}\text { Tota } \\
\text { I }\end{array}$ \\
\hline $\begin{array}{ll}\text { Plan } \\
\text { estudios }\end{array}$ & 8 & 3 & 2 & 1 & 1 & 15 \\
\hline $\begin{array}{l}\text { Personal } \\
\text { Académico }\end{array}$ & 8 & 2 & 1 & 1 & 1 & 13 \\
\hline $\begin{array}{l}\text { Personal } \\
\text { Administrativ } \\
\text { o }\end{array}$ & 8 & 3 & 2 & 0 & 1 & 14 \\
\hline $\begin{array}{l}\text { Infraestructur } \\
\text { a }\end{array}$ & 8 & 3 & 2 & 1 & 1 & 15 \\
\hline
\end{tabular}

Reacreditación de carreras de la Universidad de Casta Rica: la cumplida y lo pendiente.

Elsiana Guida-Guida

DQI: http://dx.dai.org/10.22458/caes.v12il.3508

(c) ${ }_{\mathrm{BY}}(\mathrm{F})$ 


\begin{tabular}{|l|l|l|l|l|l|l|}
\hline $\begin{array}{l}\text { Centro de } \\
\text { información y } \\
\text { recursos }\end{array}$ & 4 & 1 & 0 & 0 & 1 & 6 \\
\hline $\begin{array}{l}\text { Equipo y y } \\
\text { materiales }\end{array}$ & 1 & 3 & 1 & 0 & 1 & 6 \\
\hline $\begin{array}{l}\text { Finanzas y } \\
\text { presupuestos }\end{array}$ & 4 & 0 & 0 & 1 & 1 & 6 \\
\hline
\end{tabular}

Fuente :elaboración propia con base en datos de los Compromisos de Mejoramiento.

El componente plan de estudios es el que tiene más criterios asociados con debilidades; se citan a continuación aquellos que están presentes, con mayor frecuencia, en los CM:

- 2.1.14 Referido a que el plan de estudios debe considerar la flexibilidad curricular para satisfacer intereses específicos de la población estudiantil y para enfatizar en diferentes áreas del conocimiento: presente en siete $\mathrm{CM}$.

- 2.1.3 Referido a que se debe contar con referentes universales y las corrientes del pensamiento que fundamenten el plan de estudios: presente en seis $\mathrm{CM}$.

- 2.1.11 Se refiere a la inclusión, en el plan de estudios, de lecturas y estudio en otro idioma: presente en cinco $\mathrm{CM}$.

- 2.1.5 Hace referencia a contar con un perfil profesional de salida: presente en cuatro CM.

- 2.1.18 Solicita que los objetivos de los cursos estén redactados en términos de los aprendizajes o las competencias que se pretende lograr en los estudiantes: presente en cuatro $\mathrm{CM}$.

Infraestructura es el otro componente en el cual todos los CM de las carreras estudiadas presentaron debilidades en alguno de los ocho criterios asociados. Los de mayor frecuencia se muestran seguidamente:

Reacreditación de carreras de la Universidad de Casta Rica: lo cumplida y lo pendiente.

Elsiana Guida-Guida

D|l: http://dx.dai.org//10.22458/caes.v12ii.3508

(c) $\underset{\mathrm{BY}}{(\mathrm{i})}(\mathrm{SC}$

Artícula protegida par licencia Creative Cammans 
- 2.4.3 Disponer de un manual con las normas de seguridad, higiene y salud ocupacional: presente en once CM.

- 2.4.4 Contar con las condiciones de seguridad, higiene y salud ocupacional requeridas: presente en nueve $\mathrm{CM}$.

- 2.4.5 Contar con aulas, auditorios, laboratorios, talleres, biblioteca y otros espacios necesarios: presente en siete $\mathrm{CM}$.

- 2.4.6 Que el personal académico tenga un recinto adecuado para la atención de estudiantes: presente en seis $\mathrm{CM}$.

- 2.4.1 Se debe contar con mecanismos que atiendan la gestión para suplir las necesidades de infraestructura, de acuerdo con las particularidades y necesidades de la carrera: presente en seis CM.

En lo que respecta al componente personal administrativo, con cuatro criterios asociados, la mayoría de las 14 carreras que lo contienen, presentan debilidades en lo relativo a la importancia de contar con un plan de desarrollo profesional para el personal administrativo, el técnico y el de apoyo (criterio 2.3.4), que está presente como debilidad en siete CM; y en el criterio que se refiere a que se debe evaluar, y dar seguimiento al personal administrativo, al técnico y al de apoyo (criterio 2.3.3), presente en ocho CM.

El componente personal académico tiene doce criterios asociados, lo que lo constituye en el segundo con mayor cantidad de criterios de esta dimensión. La mayoría de los trece CM que contienen debilidades en este componente, las concentran en los criterios que se mencionan seguidamente:

- 2.2.8 Contar con plan de desarrollo para el personal académico: presente en siete $\mathrm{CM}$.

\section{Reacreditación de carreras de la Universidad de Costa Rica: lo cumplida y lo pendiente. Elsiana Guida-Guida DOI: http://dx.dai.arg//10.22458/caes.v|Zil.3508


- 2.2.9 Contar con incentivos o mecanismos de promoción para el personal académico: presente en cinco $\mathrm{CM}$.

- 2.2.11 Contar con personal académico de tiempo completo que asegure su interacción con el estudiantado y participación en actividades curriculares: presente en cinco $\mathrm{CM}$.

- 2.2.3 Garantizar que el personal académico participe en actividades de docencia, investigación y extensión social: presente en cuatro CM.

- 2.2.7 Tener mecanismos para retener a los mejores académicos, así como planes de sustitución de mediano y largo plazo: presente en cuatro CM.

\subsubsection{Dimensión: proceso educativo}

Esta dimensión está compuesta por los siguientes componentes y número de criterios:

1. Componente Desarrollo Docente, contiene cinco criterios.

2. Componente Metodología de Enseñanza- Aprendizaje, contiene siete criterios.

3. Componente Gestión de la carrera, contiene veinte criterios.

4. Componente Investigación, contiene nueve criterios.

5. Componente Extensión, contiene nueve criterios.

6. Componente Vida estudiantil, contiene diecisiete criterios.

Reacreditación de carreras de la Universidad de Casta Rica: la cumplida y lo pendiente.

Elsiana Guida-Guida

DQI: http://dx.dai.org/10.22458/caes.v12ii.3508

(c) (i) (5)

Artícula protegida par licencia Creative Commans 
Tabla 7, Universidad de Costa Rica. Total de carreras reacreditadas con debilidades encontradas en la dimensión Proceso Educativo, según componentes del Manual del año 2009, por áreas de conocimiento de la Universidad.

\begin{tabular}{|l|l|l|l|l|l|l|}
\hline $\begin{array}{l}\text { Componente } \\
\text { S } \\
\text { del Manual } \\
\text { de } \\
\text { acreditación } \\
\text { SINAES }\end{array}$ & $\begin{array}{l}\text { Número de carreras que presentan criterios con debilidades en sus } \\
\text { CM según área de conocimiento de la UCR }\end{array}$ \\
\cline { 2 - 8 } & $\begin{array}{l}\text { Ciencias } \\
\text { Sociales } \\
(8 \text { carreras } \\
\text { reacredita } \\
\text { das) }\end{array}$ & $\begin{array}{l}\text { Salud } \\
(3 \text { carreras } \\
\text { reacredita } \\
\text { das })\end{array}$ & $\begin{array}{l}\text { Ciencias } \\
\text { Agroaliment } \\
\text { arias } \\
\left(\begin{array}{l}2 \quad \text { carreras } \\
\text { reacreditada) }\end{array}\right.\end{array}$ & $\begin{array}{l}\text { Ciencias } \\
\text { Básicas } \\
(1 \text { carrera } \\
\text { reacredita } \\
\text { da) }\end{array}$ & $\begin{array}{l}\text { Letras } \\
(1 \text { carrera } \\
\text { reacredita } \\
\text { da) }\end{array}$ & Total \\
\hline $\begin{array}{l}\text { Desarrollo } \\
\text { docente }\end{array}$ & 5 & 1 & 1 & 0 & 1 & 8 \\
\hline $\begin{array}{l}\text { Metodología } \\
\text { de } \\
\text { enseñanza- } \\
\text { aprendizaje }\end{array}$ & 3 & 1 & 1 & 0 & 1 & 6 \\
\hline $\begin{array}{l}\text { Gestión de la } \\
\text { carrera }\end{array}$ & 7 & 3 & 2 & 1 & 1 & 14 \\
\hline Investigación & 6 & 2 & 0 & 0 & 1 & 9 \\
\hline Extensión & 6 & 1 & 1 & 1 & 1 & 10 \\
\hline $\begin{array}{l}\text { Vida } \\
\text { estudiantil }\end{array}$ & 8 & 2 & 0 & 1 & 1 & 12 \\
\hline
\end{tabular}

Fuente: elaboración propia con base en datos de los Compromisos de Mejoramiento.

Como se desprende de la Tabla 7, carreras de todas las áreas de conocimiento presentan criterios con debilidades en los componentes gestión de la carrera (presente en 14 carreras) y extensión. El componente gestión de la carrera es, a su vez, el que más criterios tiene en la Guía del SINAES. Los criterios más frecuentes en los CM estudiados son los siguientes:

- 3.3.19 Contar con un programa de inducción para el personal académico y administrativo nuevo: presente en seis $\mathrm{CM}$.

- 3.3.2 Contar con un plan estratégico: presente en cinco CM.

Reacreditación de carreras de la Universidad de Costa Rica: lo cumplido y lo pendiente.

Elsiana Guido-Guido

DDI: http://dx.dai.org//10.22458/caes.v12il.3500

(c) $($ i) $($ : 
- 3.3.11 Contar con mecanismos establecidos de evaluación, revisión, reflexión y actualización periódica del plan de estudios: presente en cuatro CM.

- 3.3.15 Contar con mecanismos formales de coordinación, integración, acción conjunta y seguimiento entre el personal académico que ofrece un mismo curso, del mismo nivel o eje curricular de la carrera: presente en cuatro $\mathrm{CM}$.

El otro componente de esta dimensión proceso educativo, que se presenta con mayor frecuencia, es Vida estudiantil (presente en doce carreras); el criterio en el que se localizan debilidades, con mayor frecuencia, es el 3.6.2 que se refiere a contar con normativa en materia de discapacidad, hostigamiento sexual y otras, que está presente en cuatro carreras. Otros criterios están presentes en dos carreras y son: 3.6.4 Garantizar la existencia, la divulgación y el cumplimiento de la normativa estudiantil; 3.6.15 Ofrecer al estudiantado tiempo de consulta extra-clase sobre la materia de cada curso y 3.6.14 Debe existir asesoría académica curricular para el estudiantado.

\subsubsection{Dimensión: Resultados}

Esta dimensión está compuesta por los siguientes tres componentes y número de criterios:

1. Componente desempeño estudiantil, contiene cinco criterios.

2. Componente graduados, contiene once criterios.

3. Componente proyección de la carrera, contiene un criterio.

Tal y como se desprende de la Tabla 8, todos los CM analizados presentan debilidades en criterios relacionados con los tres componentes de esta dimensión; la mayoría en los componentes graduados (trece $\mathrm{CM}$ ) y proyección de la carrera (diez CM). También se visualiza que, carreras de todas las áreas de conocimiento presentan criterios con debilidades en los componentes graduados y proyección de la carrera.

\footnotetext{
Reacreditación de carreras de la Universidad de Costa Rica: lo cumplida y lo pendiente. Elsiana Guida-Guida DQI: http://dx.dai..rg//10.22458/caes.v12il.3508$$
\text { (c) }(\text { i) }(\text { : }
$$ 
Tabla 8. Universidad de Costa Rica. Total de carreras reacreditadas con debilidades encontradas en la dimensión Resultados, según componentes del Manual del año 2009, por áreas de conocimiento de la Universidad.

\begin{tabular}{|c|c|c|c|c|c|c|}
\hline \multirow[b]{2}{*}{$\begin{array}{l}\text { Component } \\
\text { es } \\
\text { del Manual } \\
\text { de } \\
\text { acreditació } \\
\text { n SINAES }\end{array}$} & \multicolumn{6}{|c|}{$\begin{array}{l}\text { Número de carreras que presentan criterios con debilidades en sus CM } \\
\text { según área de conocimiento de la UCR }\end{array}$} \\
\hline & $\begin{array}{l}\text { Ciencias } \\
\text { Sociales } \\
(8 \text { carreras } \\
\text { reacreditad } \\
\text { as) }\end{array}$ & $\begin{array}{l}\text { Salud } \\
\text { ( } 3 \text { carreras } \\
\text { reacreditad } \\
\text { as })\end{array}$ & $\begin{array}{l}\text { Ciencias } \\
\text { Agroalimentar } \\
\text { ias } \\
(2 \quad \text { carreras } \\
\text { reacreditada) }\end{array}$ & $\begin{array}{l}\text { Ciencias } \\
\text { Básicas } \\
(1 \text { carrera } \\
\text { reacredita } \\
\text { da) }\end{array}$ & $\begin{array}{l}\text { Letras } \\
(1 \text { carrera } \\
\text { reacredita } \\
\text { da) }\end{array}$ & $\begin{array}{l}\text { tot } \\
\text { al }\end{array}$ \\
\hline $\begin{array}{l}\text { Desempeñ } \\
\text { o } \\
\text { estudiantil }\end{array}$ & 3 & 0 & 1 & 1 & 0 & 5 \\
\hline Graduados & 6 & 3 & 2 & 1 & 1 & 13 \\
\hline $\begin{array}{l}\text { Proyección } \\
\text { de le la } \\
\text { carrera }\end{array}$ & 6 & 1 & 1 & 1 & 1 & 10 \\
\hline
\end{tabular}

Fuente: elaboración propia con base en datos de los Compromisos de Mejoramiento.

Los criterios que se presentan con mayor frecuencia en el componente graduados, son los siguientes:

- 4.2.4 Contar con información actualizada sobre las condiciones del mercado laboral de la disciplina y sobre la inserción laboral de sus graduados, e informarlo a los estudiantes; presente en nueve $\mathrm{CM}$.

- 4.2.5 Contar con un sistema de información sobre sus graduados: presente en ocho CM.

- 4.2.6 Seguimiento a graduados: presente en siete CM.

- 4.2.9 Mantener el vínculo de graduados con actividades de la carrera: presente en siete $\mathrm{CM}$.

- 7 4.2.10 La carrera debe ofrecer a sus graduados oportunidades de actualización profesional: presente en siete $\mathrm{CM}$.

Reacreditación de carreras de la Universidad de Costa Rica: lo cumplida y la pendiente.

Elsiana Guido-Guido

DDI: http://dx.dai..rg//10.22458/caes.v12il.3508

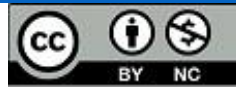

Artícula prategida par licencia Creative Cammans 
- 4.2.2 Las razones principales que explican una prolongación mayor en el período de estudios y graduación deberán estar relacionadas con situaciones atribuibles a los estudiantes o a su entorno y no a la carrera: presente en seis CM.

Diez de los quince $\mathrm{CM}$ analizados presentan debilidades en el único criterio del componente proyección de la carrera. Este criterio se refiere a que el personal docente debe contar con producción académica proveniente de su trabajo de investigación y extensión al interior de la carrera (criterio 4.3.1).

\subsubsection{Componentes: admisibilidad y sostenibilidad}

Admisibilidad y sostenibilidad son componentes no asociados a dimensiones del modelo de la agencia SINAES. De acuerdo con la agencia, los criterios del componente admisibilidad son de cumplimiento obligatorio para las instituciones de educación superior en Costa Rica (SINAES, 2009, p. 38), mientras que los criterios del componente sostenibilidad de la acreditación hacen referencia “... a la capacidad de la institución y de la carrera de asegurar la calidad, de sostener la acreditación oficial y de lograr el cumplimiento del plan de mejoramiento establecido..." (SINAES, 2009,p. 39)

Tal y como se presenta en la Tabla 9, destaca que únicamente dos carreras del área de Ciencias Sociales presentan alguna debilidad en los doce criterios asociados a la admisibilidad; en ambos casos se ubica en el criterio A1 que se refiere a que el programa o carrera debe contar con al menos una cohorte de graduados y cinco años de funcionamiento. Por otra parte, cuatro carreras presentan debilidades en alguno de los diez criterios relacionados con la sostenibilidad. Estas debilidades están en cinco criterios en los cuales se considera que la universidad no cuenta con políticas, mecanismos y lineamientos aprobados y en ejecución que: faciliten la realización del proceso de autoevaluación institucional ( criterio S1); que garanticen el desarrollo

Reacreditación de carreras de la Universidad de Costa Rica: lo cumplida y lo pendiente.

Elsiana Guida-Guida

D|l: http://dx.dai.org//10.22458/caes.v12ii.3508

(c) $($ i) $($ :

Artícula protegida par licencia Creative Commans 
de una cultura de evaluación y gestión de la calidad (criterio S.5); que garanticen el monitoreo y el seguimiento de los procesos de autoevaluación (criterio S.8); que garanticen el monitoreo y el seguimiento de la ejecución de los compromisos de mejoramiento (criterio S.9) y que garanticen el desarrollo de una cultura de evaluación y gestión de la calidad ( criterio S.10)

Tabla 9. Universidad de Costa Rica. Total de carreras reacreditadas con debilidades encontradas en los componentes Admisibilidad y Sostenibilidad, según Manual del año 2009, por áreas de conocimiento de la Universidad.

\begin{tabular}{|c|c|c|c|c|c|c|}
\hline \multirow{2}{*}{$\begin{array}{l}\text { Componentes } \\
\text { del Manual de } \\
\text { acreditación } \\
\text { SINAES }\end{array}$} & \multicolumn{6}{|c|}{$\begin{array}{l}\text { Número de carreras que presentan criterios con debilidades en sus CM según área } \\
\text { de conocimiento de la UCR }\end{array}$} \\
\hline & $\begin{array}{l}\text { Ciencias } \\
\text { Sociales } \\
\text { (8 carreras } \\
\text { reacreditadas) }\end{array}$ & $\begin{array}{l}\text { Salud } \\
(3 \quad \text { carreras } \\
\text { reacreditadas }\end{array}$ & $\begin{array}{l}\text { Ciencias } \\
\text { Agroalimentarias } \\
(2 \quad \text { carreras } \\
\text { reacreditadas) }\end{array}$ & $\begin{array}{l}\text { Ciencias } \\
\text { Básicas } \\
(1 \quad \text { carrera } \\
\text { reacreditada) }\end{array}$ & $\begin{array}{l}\text { Letras } \\
(1 \quad \text { carrera } \\
\text { reacreditada) }\end{array}$ & total \\
\hline Admisibilidad & 2 & 0 & 0 & 0 & 0 & 2 \\
\hline Sostenibilidad & 2 & 1 & 1 & 0 & 0 & 4 \\
\hline
\end{tabular}

Fuente: elaboración propia con base en datos de los Compromisos de Mejoramiento.

\section{Algunas características que comparten las carreras reacreditadas}

En este apartado se presentan características que comparten las carreras reacreditadas, considerando las dimensiones del modelo de la agencia SINAES. Para ello se parte de los hallazgos encontrados, así como del análisis de los objetivos contemplados en los CM. Antes, sin embargo, es preciso hacer dos aclaraciones, referidas a las características del modelo de la agencia, que permiten comprender y enmarcar los resultados.

Por un lado, se tiene que la causa de algunas de las debilidades presentadas se atribuye a que se contemplaron criterios que no estaban contenidos en el Manual del año 2000, con el que se acreditaron por primera vez las carreras; por esto, resulta lógico que al reacreditarse con un nuevo modelo, aparezcan como criterios incumplidos, aspectos que las carreras no

\section{Reacreditación de carreras de la Universidad de Casta Rica: lo cumplido y lo pendiente. Elsiana Guida-Guida DII: http://dx.dai.org//10.22458/caes.v12ii.3500$$
\text { (c) }(\text { i) (8) }
$$ 
habían contemplado en su primer proceso de acreditación. Por otro lado, debe de tenerse en consideración que, en el actual modelo de acreditación, un $25 \%$ de las evidencias corresponde a consultas de percepción que se realizan a diversas poblaciones, mientras que el restante porcentaje corresponde a análisis documental que se obtiene, precisamente, del análisis de documentos, guías, bases de datos, archivos de la carrera, plan de estudios, normativa, reglamentación institucional, entre otros. Esto podría ser el motivo de que, justamente, las bajas percepciones que se obtienen en los sondeos realizados, sean la razón para dar por incumplidos algunos criterios del modelo, aunque el análisis documental que haya realizado la carrera, diera como resultado, más bien, el cumplimiento de parte del requisito. Consecuentemente, esto pareciera haber generado un incremento de acciones que promueven el fortalecimiento de los planes de comunicación y divulgación, como parte de las mejoras propuestas por las carreras reacreditadas.

A partir de las consideraciones anteriores, se tienen que, en la primera dimensión denominada relación con el contexto, se encuentra un grupo de carreras reacreditadas en donde aún se tienen temas pendientes relativos a la comunicación y a la información; por consiguiente, estas carreras tienen que seguir trabajando en el establecimiento de planes estratégicos de comunicación acerca de los diferentes aspectos de la carrera que les permita, de manera sistemática y continua, comunicar e informar diversos temas a poblaciones de interés, como lo son la estudiantil, administrativa y docente.

En lo referente al componente correspondencia con el contexto, se tiene un panorama que indica la importancia de que las carreras reacreditadas sigan implementando estrategias para una efectiva vinculación con su comunidad académica. Para esto, se han propuesto objetivos tendientes a la evaluación integral de la propuesta curricular y el seguimiento al plan estratégico (en aquellos casos en que esta relación con el contexto, ya estaba contemplada

Reacreditación de carreras de la Universidad de Casta Rica: lo cumplido y lo pendiente.

Elsiana Guida-Guido

DDI: http://dx.dai..rg//I0.22458/caes.v12il.3508

(c) (i) (5)

Artícula protegida par licencia Creative Cammans 
en los documentos de planificación de la carrera), entre otros aspectos. Al mismo tiempo, se trata de carreras que deben seguir realizando esfuerzos por brindarle experiencias prácticas al estudiantado, a partir del entorno en el que la disciplina se desarrolla. Con esta finalidad se han propuesto, entre otros objetivos, la actualización o fomento de vínculos con diferentes instancias gubernamentales y no gubernamentales para favorecer la participación del estudiantado en proyectos relacionados con las necesidades emergentes de la población, o bien, fomentar el vínculo con las industrias, en los distintos cursos de la carrera.

La actualización del plan de estudios es una tarea pendiente y, a la vez, una acción constante en la que las carreras reacreditadas realizan esfuerzos de manera continua, por mantener propuestas curriculares que respondan al estado actual de avance o desarrollo de la disciplina o profesión-estado del arte- y a la realidad del contexto nacional e internacional, así como al mercado laboral.

En la segunda dimensión, relativa a los recursos, destaca lo relacionado a la flexibilidad de la propuesta curricular. Debido a esta debilidad recurrente, las carreras plantean, entre otros aspectos, la elaboración de un nuevo plan de estudios, en donde se revise toda la fundamentación disciplinar y profesional, así como la propuesta de cursos con diversos grados de virtualidad; sumado a lo anterior, algunas plantean el mejoramiento de los mecanismos de divulgación con que cuentan, porque se parte de la consideración que cuentan con suficientes mecanismos de flexibilidad curricular, pero estos no son totalmente conocidos por el estudiantado.

El tema de los referentes universales se intenta abordar también por medio de revisiones curriculares y, además, por medio de su divulgación, porque se le atribuyen a estas debilidades, causas relacionadas con el desconocimiento, precisamente por falta de divulgación. Además, ante la

\section{Reacreditación de carreras de la Universidad de Casta Rica: lo cumplido y lo pendiente. Elsiana Guida-Guido DDI: http://dx.dai..rg//10.22458/caes.v12il.3508$$
\text { (c) (1) (8) }
$$ 
necesidad de contar con un perfil de salida, las carreras proponen la actualización de sus propuestas curriculares y de sus perfiles de salida, así como reflexiones en torno a su objeto de estudio.

En esta dimensión que cuestiona la propuesta curricular, se tiene también que, gran parte del conjunto de carreras reacreditadas, se propone mejorar la internacionalización curricular y la incorporación de lecturas en otro idioma en los diferentes cursos de la carrera. También se encontró que, para una parte de ellas, los objetivos de los cursos no siempre están redactados en términos de los aprendizajes o las competencias que se espera alcance el estudiantado, por lo que se realizan esfuerzos para lograr este objetivo y cumplir con el criterio.

En cuanto a la infraestructura, destaca la carencia de manuales con las normas de seguridad, higiene y salud. Ante esta situación, algunas carreras se proponen su elaboración, pero otras atribuyen las causas, de la debilidad, al desconocimiento de los manuales existentes por parte de las poblaciones consultadas, por ello lo intentan mejorar por medio de la elaboración de planes de comunicación, en donde se incluya información al respecto, de manera tal que se aumente el porcentaje del profesorado, estudiantes y personal administrativo que opina favorablemente sobre las condiciones de higiene, seguridad y salud ocupacional con que se cuenta.

Por otro lado, los aspectos relacionados con la insuficiencia de las instalaciones siguen estando pendientes para una parte de las carreras reacreditadas, a pesar de las inversiones realizadas y de los proyectos desarrollados en la UCR, durante los últimos años, tanto con financiamiento del Proyecto de Mejoramiento Institucional, el Banco Mundial, como con presupuesto ordinario y de vínculo externo

Reacreditación de carreras de la Universidad de Costa Rica: lo cumplida y lo pendiente.

Elsiana Guida-Guida

DDI: http://dx.dai.org//0.22458/caes.v12il.3508

(c)

Artícula prategida par licencia Creative Cammans 
de la Universidad. ${ }^{3}$ Ante la debilidad detectada, la mayor parte de las carreras se proponen la habilitación o remodelación de espacios como aulas, laboratorios y salas especiales para la realización de actividades didácticas; algunas pocas se proponen construcciones de edificios y otras optan por algo más general como realización de gestiones ante las autoridades, con la finalidad de disponer de instalaciones físicas que satisfagan las necesidades detectadas. Vale señalar que muchas de las carreras reacreditadas se han visto directamente beneficiadas con estas inversiones y con la construcción de edificios de aulas y laboratorios para carreras del área de Ciencias Sociales, Ciencias Básicas, Salud y Ciencias Agroalimentarias, así como mejoras en edificaciones de las otras áreas. ${ }^{4}$

Dentro de las variadas limitaciones físicas, las carreras reacreditadas buscan mejorar la disponibilidad y la suficiencia del espacio destinado a la atención al estudiantado; aunque, ante la situación económica de la universidad y del país, algunas carreras han innovado y propuesto la implementación de medios electrónicos, como una forma alternativa a la atención extraclase presencial.

En lo que se refiere al personal administrativo, destacan dos grandes retos: por un lado, la elaboración de planes de desarrollo profesional para el personal administrativo, el técnico y el de apoyo, acorde con las necesidades del proceso educativo y las demandas institucionales; y por otro, la incorporación de un sistema de evaluación del cumplimiento de sus funciones que promueva prácticas evaluativas en la carrera.

En lo que atañe al personal académico, algunas de las carreras reacreditadas plantean como objetivos ya sea crear, revisar o mejorar el documento integrado con el plan de desarrollo de

\footnotetext{
${ }^{3}$ Según datos del Informe Anual del Rector, 2019-2020, durante el período 2016-2020 se realizó una inversión en infraestructura en la UCR, que abarcó más de 115 mil metros cuadrados (Universidad de Costa Rica, 2020, p. 159)

${ }^{4}$ Debe de tenerse en cuenta que, algunas de las carreras estudiadas, fueron reacreditadas antes de que se contara con la nueva infraestructura institucional.
}

\section{Reacreditación de carreras de la Universidad de Casta Rica: lo cumplido y lo pendiente. Elsiana Guida-Guida DDI: http://dx.dai..rg//10.22458/caes.v12il.3508$$
\text { (c) (i) (8) }
$$ 
este grupo; además, dadas las dificultades para que todo el personal académico participe en actividades de docencia, investigación y extensión social, se proponen como objetivo el contar con mayores recursos que permita contratar docentes que se dediquen además a investigar y a desarrollar proyectos de acción social.

En lo que respecta a la manera en que se puede retener al personal académico, los esfuerzos de las carreras se enfocan en la disminución del interinazgo; también plantean objetivos tendientes a promover la contratación de docentes a tiempo completo. Adicionalmente, para propiciar su desarrollo profesional en la Universidad, se piensa en el mejoramiento docente en cuanto a su formación en didáctica universitaria, así como en la divulgación tanto de las actividades de capacitación para docentes, como de los mecanismos e incentivos a los que tiene acceso para su desarrollo profesional, como mecanismos que pueden implementarse para propiciar su desarrollo profesional en la Universidad.

En la tercera dimensión denominada proceso educativo, destacan los retos relacionados con el fortalecimiento de los mecanismos establecidos de evaluación, revisión, reflexión y actualización periódica del plan de estudios. En este sentido, se plantean objetivos que buscan, justamente, la implementación de dichos mecanismos, en los casos en que la causa se atribuye a su inexistencia, pero cuando las reflexiones llevan a la carrera a definir que la causa de estas debilidades se debe al desconocimiento de su existencia, los objetivos planteados buscan divulgar esos mecanismos ya existentes, a las poblaciones de interés, por lo tanto, la mejora queda consignada, nuevamente, en los planes de comunicación.

Además, destaca el trabajo aún pendiente en lo referente a manuales de inducción para el personal académico y administrativo, por lo que los esfuerzos se centran aquí en la elaboración e implementación de esos documentos. Tampoco tienen, todas las carreras

Reacreditación de carreras de la Universidad de Costa Rica: lo cumplida y lo pendiente.

Elsiana Guida-Suida

DIII: http://dx.dai.org//1.22458/caes.v12il.3508

(c) $($ ) () ()

Artícula prategida par licencia Creative Cammans 
acreditadas, planes estratégicos que orienten su desarrollo y funcionamiento, porque este es uno de los instrumentos de planificación que no se solicitaba en el Manual con el cual las carreras se acreditaron por primera vez.

Otros aspectos que deben reforzase en algunas carreras reacreditadas son los mecanismos formales de coordinación, integración, acción conjunta y seguimiento entre el personal académico que ofrece un mismo curso, del mismo nivel o eje curricular de la carrera. Esto, si bien no se presenta en muchas carreras, ha provocado en las carreras dos vertientes de acciones: por un lado, se busca la generación de esos mecanismos y una mejor coordinación del personal docente pero, por otro lado, ha llevado a otras carreras a replantearse antes una reflexión sistemática acerca del objeto de estudio de la carrera.

En los criterios relacionados con la vida estudiantil, está presente el tema relativo al desconocimiento, por parte de las poblaciones estudiantiles, acerca del cumplimiento de diversa normativa, por ejemplo, la de discapacidad y hostigamiento sexual; por ello, las estrategias planteadas por las carreras reacreditadas van dirigidas a la incorporación de estos temas en los planes de comunicación para aumentar en el estudiantado, tanto el nivel de conocimiento de esta normativa, como su cumplimiento. También los planes de comunicación incluyen lo relativo a la divulgación de la normativa estudiantil, en general.

En la cuarta y última dimensión del modelo de acreditación, denominada resultados, destacan las carreras que requieren investigar más acerca de los motivos de la prolongación del período de estudios y graduación de sus estudiantes (que son atribuibles al estudiantado o a su entorno, y no a la carrera). En este sentido, los objetivos propuestos se pueden agrupar en dos: por un lado los que buscan realizar una evaluación integral del plan de estudios, para determinar modificaciones para su mejora, y los que intentan abordar el tema por medio de otras estrategias como reducir los tiempos

Reacreditación de carreras de la Universidad de Costa Rica: lo cumplida y la pendiente.

Elsiana Guido-Guido

DQI: http://dx.dai.org/10.22458/caes.v12il.3508

(c) $($ ) () ()

Artícula prategida par licencia Creative Cammans 
de ejecución de los trabajos finales de graduación, o bien, realizar investigaciones que permitan implementar estrategias para solventar las situaciones académicas propias de la carrera, que afectan la prolongación de los estudios de la población estudiantil.

Otro aspecto que presenta más de la mitad de las carreras reacreditadas analizadas se refiere a la necesidad de mantener información actualizada acerca del mercado laboral de la disciplina y de la inserción laboral de las personas graduadas. Ante este panorama los objetivos se dirigen, en su mayoría, al establecimiento de sistemas de información de personas graduadas para dar seguimiento a su incorporación y obtener su opinión acerca del mercado laboral con la intención de identificar mejoras en el plan de estudios y atender diversas necesidades de capacitación. Otras acciones apuntan a mejorar los mecanismos que utiliza la carrera para informar al estudiantado activo, sobre las condiciones del mercado laboral. Vale indicar que, este punto se relaciona, directamente, con la debilidad referida a la necesidad de implementar sistemas de seguimiento a personas graduadas.

El elemento más notorio de esta dimensión se refiere a la necesidad de mantener activos los vínculos entre las carreras y las personas graduadas; para su abordaje, se han propuesto, en general, acciones en por lo menos tres direcciones: por un lado, un grupo de carreras aboga por la creación de programas de educación continua que promuevan espacios de actualización, intercambio y divulgación de acciones de extensión docente; por otro lado, se propone fortalecer la vinculación de la carrera con la población graduada para la realimentación del plan de estudios e identificación de necesidades de actualización profesional y, otro grupo de carreras apuesta al desarrollo de un proceso de información y divulgación a la población graduada, con el fin de mantenerla al tanto de lo que sucede.

Finalmente, el componente proyección de la carrera, que cuenta únicamente con un criterio, se refiere a que el personal docente debe contar con producción académica proveniente de su trabajo de

Reacreditación de carreras de la Universidad de Casta Rica: lo cumplido y lo pendiente.

Elsiana Guida-Guido

DQI: http://dx.dai.org//1.22458/caes.v12ii.3508

(c) (i) (5)

Artícula protegida por licencia Creative Commans 
investigación y extensión al interior de la carrera. La situación asociada aquí es que este criterio está vinculado a tres estándares de difícil cumplimiento, dadas las condiciones académicas, financieras y administrativas de la Universidad, a saber:

- Estándar 32. Al menos un 50\% del personal académico a tiempo completo debe contar con producción académica.

- Estándar 33. Al menos un $25 \%$ del personal a tiempo parcial debe contar con producción académica indexada anualmente.

- Estándar 34. Al menos cada dos años, el personal académico de la carrera a tiempo completo debe participar con ponencias o conferencias en foros nacionales o internacionales.

Los objetivos propuestos para solventar esta debilidad, buscan aumentar la producción académica del personal docente, potenciando la investigación en equipos, desarrollar e implementar planes y estrategias para incrementar la producción de publicaciones del personal docente e incrementar la participación académica del personal docente, en conferencias 0 en foros nacionales 0 internacionales, entre otros.

\section{Conclusiones}

Históricamente, las carreras de la UCR se han caracterizado por su compromiso con la calidad académica y con la excelencia de sus procesos y resultados, incluso desde mucho antes de que los procesos de acreditación tomaran auge a nivel mundial y en el sistema de educación superior costarricense. Aunado a lo anterior y, dados los hallazgos presentados aquí, es posible afirmar que las reacreditaciones de carreras brindan la oportunidad de continuar con la mejora, y las innovaciones, en temas como la pertinencia de la propuestas curriculares, el ejercicio de la docencia, la articulación entre docencia, investigación y acción social y el fortalecimiento de los vínculos con poblaciones que tradicionalmente han estado alejadas de la universidad, como los son las personas graduadas o empleadoras. Además,

\section{Reacreditación de carreras de la Universidad de Costa Rica: lo cumplida y lo pendiente.}

Elsiana Guida-Guida

DDI: http://dx.dai.org//0.22458/caes.v|2il.3508

(c) 
se visualiza que muchos aspectos relacionados con el plan de estudios, personal académico o infraestructura, por ejemplo, no se logran superar desde el ámbito académico de la carrera, pues tienen relación con situaciones presupuestarias, políticas institucionales o decisiones más generales, que se vinculan de manera más estrecha con una acreditación de corte institucional.

Como se presentó aquí, los CM tienen debilidades en todas las dimensiones del modelo; asimismo, contienen criterios con debilidades en todos los componentes. Los componentes con mayor cantidad de criterios asociados a una debilidad son correspondencia con el contexto, plan de estudios, personal académico, infraestructura, gestión de la carrera, investigación, vida estudiantil y graduados. Se considera que diversas características del funcionamiento de la Universidad propiamente, así como del modelo utilizado por la agencia en concreto, contribuyen a que se presenten debilidades en la mayoría de los criterios del modelo.

Los aspectos aún pendientes, los definidos como urgentes, así como algunos de los esfuerzos institucionales desarrollados por la UCR, se pueden agrupar en siete grandes temas, a saber: 1 Algunas carreras cuentan con mecanismos poco ágiles para sistematizar, analizar, comprender el entorno y reaccionar ante sus necesidades y demandas. Esto se visualiza claramente en las debilidades vinculadas con la relación y correspondencia con el contexto y en la consecuente desactualización e inflexibilidad de sus propuestas curriculares; además, en la desactualización de los perfiles de egreso o de salida y en la insuficiente internacionalización curricular. Al respecto, debe señalarse el esfuerzo institucional y sostenido que, desde el año 2015, realiza la UCR mediante la ejecución de acciones que buscan la actualización de los perfiles de egreso; esto ha generado que, en el período 20152019, se haya logrado la actualización del perfil de egreso de treinta carreras de esta

Reacreditación de carreras de la Universidad de Costa Rica: lo cumplida y lo pendiente.

Elsiana Guida-Guida

DDI: http://dx.dai.org//1.22458/caes.v12ii.3508

(c) (1) (8)

Artícula prategida par licencia Creative Cammans 
institución (Universidad de Costa Rica, 2020a, p.4). De este modo, diversa normativa reciente emitida por la Universidad, así como los requerimientos de la agencia, han incidido en que se revise la actualización y pertinencia de las propuestas curriculares y los perfiles de salida, de manera que respondan a los retos nacionales e internacionales, desde una visión de Universidad pública.

2 Los mecanismos de comunicación y divulgación implementados por algunas carreras, no siempre funcionan de manera permanente y articulados en un plan, de manera tal que sus poblaciones de interés cuenten con las informaciones pertinentes y suficientes y se obtengan, de este modo, percepciones favorables, o aceptables, ante todo lo que se les consulta, de acuerdo con los requerimientos del modelo. Esta situación queda evidenciada en la gran cantidad de debilidades que deben integrarse en planes estratégicos de comunicación. La prevalencia de esta debilidad puede deberse, también, a los requerimientos del mismo modelo de acreditación y a los criterios basados en la percepción.

3 Tradicionalmente, algunas de las carreras han mantenido poco contacto con su población graduada y cuentan con insuficientes espacios permanentes de diálogo, entre otros motivos porque a este sector no se le ha considerado ni como informante clave y parte fundamental de los mecanismos de actualización curricular, ni tampoco como portadores de información sobre el mercado laboral y sus condiciones. Esta falencia queda clara con la desactualización de la información disponible acerca del mercado laboral de la disciplina y la inserción laboral de las personas graduadas. Llama la atención la frecuencia de estas debilidades, siendo que el país cuenta con diversos estudios que recogen y sistematizan esta información de manera periódica, tales como los desarrollados por el Consejo Nacional de Rectores (CONARE), la Oficina de Planificación de la Educación Superior (OPES) y el Observatorio Laboral de Profesiones, que incluyen, entre otros temas, seguimiento de la condición laboral, empleadores y personas graduadas.

Reacreditación de carreras de la Universidad de Costa Rica: lo cumplida y lo pendiente.

Elsiana Guida-Guida

DQI: http://dx.dai.org/10.22458/caes.v12il.3508

(c) $($ i) (8)

Artícula prategida par licencia Creative Cammans 
4 Otras de las carreras reacreditadas carecen, además, de información unificada, sistematizada, bases de datos y sistemas de información que les permita tomar decisiones académicas, basadas en el análisis de datos. Sobre el particular debe indicarse el gran avance logrado por la UCR en la atención de este reto, con la creación del Sistema de Información Institucional de Autoevaluación y Gestión de la Calidad (SIIAGC). Este sistema, único, pretende atender "ágil y eficientemente las demandas de unidades académicas, oficinas administrativas, autoridades universitarias y del Centro de Evaluación Académica requeridas para los procesos de evaluación, autoevaluación, certificación, acreditación, reacreditación de carreras y servicios institucionales, además del seguimiento los compromisos de mejora" (Centro de Evaluación Académica, 2020). El primer módulo se puso en marcha en el año 2019 y facilita la consulta de información sobre población estudiantil y graduada, así como del personal docente, administrativo, técnico y de apoyo. Se espera desarrollar, en otros módulos, información de personal administrativo, vinculación, proyectos, planes de estudio e inteligencia de negocios. (Gómez, M., 2018). También, al permitir el acceso a la información requerida por las carreras para los procesos de autoevaluación, acreditación y gestión de la calidad, (Universidad de Costa Rica, 2018), se constituye en una respuesta eficaz a la debilidad detectada en varias carreras.

5 La formación continua del profesorado que garantice una docencia de calidad, sigue siendo un tema urgente, así como mejorar sus condiciones de contratación para fortalecer las tres áreas sustantivas de la universidad, como lo son la docencia, la investigación y la acción social. La UCR ha dado grandes apoyos a las carreras para el mejoramiento del personal docente en aspectos de su formación en didáctica universitaria. Las iniciativas institucionales al respecto van favoreciendo que, poco a poco, se promueva el mejoramiento didáctico y pedagógico del cuerpo docente, para afrontar retos también relativos a la virtualidad de la docencia, el uso de las tecnologías y la flexibilización curricular. Algunas de las iniciativas promovidas desde la Vicerrectoría de Docencia en los últimos doce años han sido la creación

Reacreditación de carreras de la Universidad de Costa Rica: lo cumplida y la pendiente.

Elsiana Guida-Guida

DII: http://dx.dai.org//1.22458/caes.v12ii.3508

(c) $($ i) (8) 
de la Unidad de Apoyo a la Docencia mediada con TIC'S (METICS) que inició funciones en el año 2006; dos años después se creó la Red Institucional de Formación y Evaluación Docente (RIFED) (Universidad de Costa Rica, 2008); posteriormente, en el año 2014 inició formalmente el proyecto Docencia Multiversa (Universidad de Costa Rica, 2017a, p.3). Deben mencionarse también los aportes realizados por el Programa de Tecnologías Educativas Avanzadas (PROTEA), del Decanato de la Facultad de Educación, desde el año 2002.

Adicionalmente, la UCR ha desarrollado en los últimos años no solo esfuerzos importantes para reducir el interinazgo y cumplir con las Políticas de la Universidad de Costa Rica 20162020 de retención del personal interino, sino también para comprender este fenómeno en todas sus dimensiones históricas, institucionales y personales (Universidad de Costa Rica, 2020b); en este sentido destaca la promulgación de normativa para atender este tema, por parte de la Rectoría y Vicerrectoría de Docencia, durante el período comprendido entre los años 2016 y $2018^{5}$.

6 La producción académica de una parte del personal docente es escasa, y esto dificulta cumplir con los estándares relacionados que plantea el modelo de la agencia, por cuanto gran parte de la carga laboral se dedica a la docencia, sobre todo la del personal docente contratado por una jornada parcial. Al respecto, los esfuerzos de las carreras se dirigen al desarrollo de planes y estrategias que fomenten el incremento de la producción académica en las áreas de investigación, docencia y acción social, así como al establecimiento de ejes de trabajo conjunto entre las carreras, centros de investigación y posgrados relacionados. Para una universidad con la importancia y el prestigio de la UCR, es contradictorio presentar debilidades en estos criterios debido a la gran cantidad de proyectos de investigación que se desarrollan en todas las áreas del saber, en donde, por ejemplo, en el periodo comprendido

\footnotetext{
${ }^{5}$ Por ejemplo, la Resolución R- 139- 2017 de la Rectoría, y las Circulares de la Vicerrectoría de Docencia VD- 43-2017, VD-
} 15-2018 y VD- 3-2020

Reacreditación de carreras de la Universidad de Costa Rica: lo cumplido y lo pendiente.

Elsiana Guido-Guido

DDI: http://dx.dai.arg/l0.22458/caes.v|2il.3508

(c) 
entre el 2015 y el 2019, la cantidad de proyectos de investigación fue de 6993 (Universidad de Costa Rica, 2020a, p.28) y la UCR se ubica dentro de las 500 mejores universidades del mundo, de acuerdo con la Clasificación mundial de universidades QS del 2016-2017, (en inglés, QS World University Rankings) (Vicerrectoría de Investigación, 2020).

En este aspecto debe mencionarse la reciente normativa emitida por la Vicerrectoría de Investigación que pude incidir de manera directa en el grupo de carreras que presenta esta dificultad, por cuanto se exige que quien investigue, deba presentar en un plazo no mayor a dos años, una vez que concluya la investigación, “...al menos una obra de carácter académico, sea un artículo en una revista arbitrada e incluida en índices que evalúen con criterios de calidad, un capítulo o un libro publicado por editoriales reconocidas institucionalmente, u otro medio afín, según las características de su campo académico" (Universidad de Costa Rica, 2018, p.22)

7 Insuficiencia de algunas políticas institucionales, de docencia, administración, investigación y acción social para apoyar, de manera directa, necesidades y requerimientos comunes de las carreras, que facilitarían la superación de debilidades relacionadas con aspectos específicos, tales como la elaboración de normas de seguridad, higiene y salud ocupacional y la ejecución de planes de desarrollo profesional para el personal administrativo junto con la evaluación de su desempeño. En este tema, destacan los programas de inducción y formación del personal docente que asume tareas directivas, desarrollados en la institución, lo que facilita que estas personas cuenten con herramientas para la gestión académica y administrativa de la carrera. Ejemplo de lo anterior lo constituye la iniciativa Direcciona UCR, impulsada por la Vicerrectoría de Docencia, que pretende el desarrollo de la gestión académica administrativa universitaria y está dirigida al personal directivo de Escuelas, Decanaturas y Sedes Universitarias de la Universidad. El objetivo es contribuir con el

\section{Reacreditación de carreras de la Universidad de Costa Rica: lo cumplido y lo pendiente.}

Elsiana Guida-Guida

DDI: http://dx.dai.org//0.22458/caes.v|2il.3508

(c) ${ }_{\mathrm{BY}}(\mathrm{No}$ 
desarrollo del talento de las autoridades académicas en el ejercicio de sus actividades directivas para optimizar la gestión de las personas, sus equipos, los recursos de la institución y la toma de decisiones; para ello, desarrolla temas tales como las funciones directivas, gestión financiera, de recursos humanos y de proyectos. (Vicerrectoría de Docencia, s.f.) Para concluir y ante este panorama de avances, desafíos pendientes y definición de temas urgentes de tratar, surgen las preguntas: ¿Cuál es la responsabilidad de la Universidad, como un todo, para procurar que las carreras reacreditadas logren superar estas debilidades?, ¿cuáles otras políticas institucionales deben promoverse?, ¿cuáles apoyos concretos requieren las carreras universitarias para gestionar su calidad y superar las debilidades encontradas en sus procesos de reacreditación?, ¿desde el CONARE, cuáles acciones integradas pueden gestionarse para reducir las debilidades de las carreras?, ¿ de qué manera contribuye concretamente el profesorado, estudiantes y personal docente en el mejoramiento de las carreras?, ¿se debe impulsar otra visión de Universidad (de docencia y de investigación) para fortalecer la calidad de las carreras?, ¿de qué manera las demandas de las carreras, derivadas de sus procesos de reacreditación, pueden modificar o incidir sobre los sistemas institucionales para provocar cambios que favorezcan la mejora continua?,¿cuál es la responsabilidad de la Universidad en el mantenimiento de los estándares de calidad de las carreras?, con la acreditación institucional, ¿podrán las carreras concentrarse en mejorar sus aspectos académicos propios y delegar en otras instancias institucionales aquellos temas que dependen de decisiones políticas más amplias?

Desde la perspectiva de las agencias acreditadoras, surgen interrogantes como ¿cuáles criterios son fundamentales para garantizar la calidad de una carrera universitaria ?, ¿tienen el mismo peso académico los criterios de calidad para carreras de universidades diferentes?, ¿el modelo atiende la diversidad de universidades y sistemas de aseguramiento de la calidad?, ¿de qué manera las agencias pueden favorecer, con sus modelos, cambios

Reacreditación de carreras de la Universidad de Costa Rica: lo cumplido y lo pendiente.

Elsiana Guida-Guida

DQI: http://dx.dai.org/10.22458/caes.v12il.3508

(c) (1) (8)

Artícula prategida par licencia Creative Cammans 
institucionales en las instituciones de educación superior?, ¿cuál visión de calidad se fomenta en las carreras reacreditadas?, ¿esa visión de calidad atiende a las necesidades y trayectoria de las carreras y las instituciones?, ¿de qué manera el aseguramiento de la calidad y la sostenibilidad de los procesos de mejora que se proponen, toman en cuenta la diversidad de las necesidades institucionales?, las debilidades institucionales deben pesar en los CM de las carreras reacreditadas, de igual modo que las debilidades propias?, ¿se deben seguir reacreditando carreras con el mismo modelo utilizado para la acreditación?, ¿significa realmente la reacreditación un cumplimiento y mayor aseguramiento de los estándares de calidad de las carreras acreditadas?, ¿ se propone con la reacreditación de carreras un aseguramiento de la calidad basado en un cumplimiento de requisitos o en un compromiso con la mejora?, ¿qué aspectos debería enfatizar un modelo para reacreditación de carreras?, ¿deben seguirse limitando las carreras que optan por la reacreditación, a ponderar los criterios del modelo de una agencia, o deberían de considerar, en su proceso de autoevaluación, otros aspectos que consideren fundamentales para el afianzamiento de la calidad, el posicionamiento de la educación superior como un bien público, el fortalecimiento de sus sistemas de gestión de calidad, las vulnerabilidades institucionales así como su capacidad para adecuarse a situaciones críticas, diversas y cambiantes?, ¿las percepciones de las poblaciones de interés para las carreras, cuál porcentaje deberían de significar, dentro de un modelo? , ¿cómo son definidos los estándares?, ¿deben los estándares basarse en percepciones?, cuáles estímulos pueden aumentar el número de carreras que se acreditan y reacreditan?, ¿cuáles aspectos de la calidad son los urgentes de atender?

Como cuestionamiento final, emergen interrogantes tales como ¿las carreras reacreditadas están formando mejores seres humanos?, ¿por qué motivos la divulgación desempeña ahora un papel primordial en los $\mathrm{CM}$ ?, ¿por qué motivos las percepciones de las poblaciones consultadas en los procesos de autoevaluación para reacreditación, son negativas o se

Reacreditación de carreras de la Universidad de Costa Rica: lo cumplida y la pendiente.

Elsiana Guida-Guida

DIII: http://dx.dai.org//1.22458/caes.v12il.3508

(c) $($ ) () () 
muestran tan desinformadas? Se han preguntado la agencia, la universidad y las carreras, ¿qué hay detrás del no cumplimiento de aspectos del $\mathrm{CM}$ en una reacreditación? O ¿por qué lo pendiente y lo urgente no siempre aparece como cumplido en una reacreditación?

Reacreditación de carreras de la Universidad de Costa Rica: lo cumplido y lo pendiente.

Elsiana Guido-Suida

DUI: http://dx.dai.org/l0.22458/caes.v|2il.3508

(c) (1) (8)

Artícula prategida par licencia Creative Cammans 


\section{Referencia}

Centro de Evaluación Académica. (2020). Sistema de Información Institucional para la Autoevaluación y la Gestión de la Calidad. Recuperado de: http://www.cea.ucr.ac.cr/index.php/departamentos/diea/siiagc

Centro Interuniversitario de Desarrollo. CINDA. (2016) Educación Superior en Iberoamérica. Informe Nacional: Costa Rica. Elaborado por Jorge Mora Alfaro. Recuperado de: https://cinda.cl/publicacion/educacion-superior-en-iberoamerica-informe-2016informe-nacional-costa-rical

Consejo Superior Universitario Centroamericano. CSUCA. (2016). Autoevaluación y gestión de la calidad en las universidades centroamericanas. Presentación en power point, Francisco Alarcón. DIGED, USAC. Ciudad de Guatemala. 11 de mayo 2016.

Gómez, M. (2018). Nuevo sistema agiliza procesos de autoevaluación y gestión de la calidad. Universidad de Costa Rica. Centro de Informática. Recuperado de: https://ci.ucr.ac.cr/noticias/nuevo-sistema-agiliza-procesos-de-autoevaluacion-ygestion-de-la-calidad

Ley 8256. Ley del Sistema Nacional de Acreditación de la Educación Superior (SINAES). Diario Oficial La Gaceta No.94. Costa Rica. (17 mayo 2002).

Red Iberoamericana de Acreditación de la Educación Superior. RIACES. (s.f). Glosario Internacional RIACES de Evaluación de la Calidad y Acreditación. Recuperado de: http://www.riaces.org/v1/index.php/servicios/glosario-riaces

Sistema Nacional de Acreditación de la Educación Superior. SINAES. (2000). Manual de Acreditación -Convocatoria año 2000.

Sistema Nacional de Acreditación de la Educación Superior. SINAES (11de julio 2001a). Oficio SINAES-112-2001.

Sistema Nacional de Acreditación de la Educación Superior. SINAES (26 de julio 2001b). Oficio-SINAES-111-2001.

Sistema Nacional de Acreditación de la Educación Superior. SINAES. (2009) Manual de Acreditación oficial de carreras de grado del Sistema Nacional de Acreditación de la Educación Superior.

Reacreditación de carreras de la Universidad de Costa Rica: lo cumplido y lo pendiente.

Elsiana Guida-Guida

DII: http://dx.dai.org/l0.22458/caes.v12il.3508

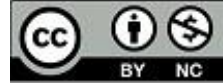

Artícula prategida par licencia Creative Cammans 
Sistema Nacional de Acreditación de la Educación Superior. SINAES. (20 agosto, 2019). Preguntas frecuentes. ¿Qué se entiende exactamente por reacreditada? https://www.sinaes.ac.cr/index.php/preguntas-frecuentes

Sistema Nacional de Acreditación de la Educación Superior. SINAES. (2020a). Sobre SINAES. Conformación del sistema. Recuperado de https://www.sinaes.ac.cr/index.php/home/conformacion-del-sistema

Sistema Nacional de Acreditación de la Educación Superior. SINAES. (16 agosto, 2020b). Lista de acreditaciones y re acreditaciones 2001-2020 (VIGENTES) - última acta con acreditaciones incorporada 4 de agosto de 2020, Acta 1424-2020. Recuperado de https://www.sinaes.ac.cr/index.php/home/carrera

Universidad de Costa Rica. Centro de Evaluación Académica. Compromisos de Mejoramiento de carreras reacreditadas. Falta fecha

Universidad de Costa Rica. Vicerrectoría de Docencia. (2017a). Proyecto Docencia Multiversa. Informe de Labores 2016.

Universidad de Costa Rica. Vicerrectoría de Docencia (19 setiembre, 2017). CIRCULAR VD43-2017

Universidad de Costa Rica. Vicerrectoría de Docencia (19 setiembre, 2017). CIRCULAR VD$15-2018$

Universidad de Costa Rica. Vicerrectoría de Docencia (19 setiembre, 2017). CIRCULAR VD3-2020

Universidad de Costa Rica. Rectoría (2020a). Informe Anual del Rector 2019-2020. San José, Costa Rica.

Universidad de Costa Rica. Vicerrectoría de Docencia. (7 de diciembre, 2018). CIRCULAR VD-40-2018.

Universidad de Costa Rica. Vicerrectoría de Docencia. (2020b). Análisis del interinazgo docente en la Universidad de Costa Rica. Recuperado el 07 de setiembre, 2020 de http://www.kerwa.ucr.ac.cr/handle/10669/80979

Reacreditación de carreras de la Universidad de Costa Rica: lo cumplido y lo pendiente.

Elsiana Guida-Guida

DDI: http://dx.dai..rg//10.22458/caes.v12il.3508

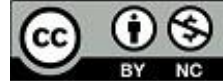

Artícula prategida par licencia Creative Cammans 
Vicerrectoría de Docencia. Universidad de Costa Rica. (s.f.). Direcciona UCR. Recuperado de: http://vd.ucr.ac.cr/nosotros/direcciona-ucr/

Vicerrectoría de Investigación. Universidad de Costa Rica (02 de octubre,2020). UCR subió 30 lugares en ranking mundial de universidades (Comunicado de prensa). Recuperado de mundo

Reacreditación de carreras de la Universidad de Costa Rica: lo cumplido y lo pendiente.

Elsiana Guida-Guida

DII: http://dx.dai.org//10.22458/caes.v12ii.3508

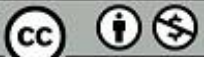

Artícula prategida par licencia Creative Cammans 